\title{
Research Paper \\ The Mediating Role of Cognitive Emotion Regulation in the Relationship of Early Maladaptive Schemas With Spouse Abuse
}

\author{
Ali Zade-Mohammadi ${ }^{1}$ (1) ${ }^{*}$ Hamid Kordestanchi Aslani $^{1}$ (),
}

1. Department of Clinical Psychology, Family Research Institute, Shahid Beheshti University, Tehran, Iran

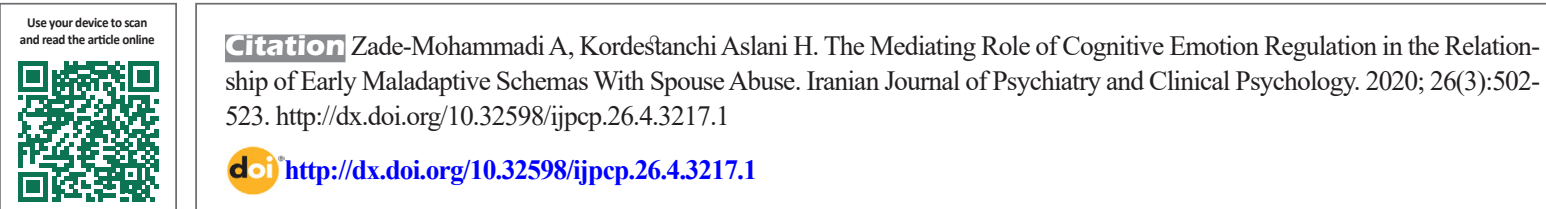

Received: 20 Oct 2019

Accepted: 02 Jun 2020

Available Online: 01 Oct 2020

Key words:

Cognitive emotion regulation, Early maladaptive schemas, Spouse abuse, Emotional dysregulation

\begin{abstract}
A B S TRACT
Objectives This study aimed to examine the mediating role of cognitive emotion regulation in the relationship of early maladaptive schemas with spouse abuse.

Methods In this descriptive-correlational study, 324 married adults (226 females, 98 males) living in Tehran, Iran in 2017 were selected using a convenience sampling technique. They completed the revised Conflict Tactics Scales (CTS-2), the Young Scale Questionnaire-Short Form (YSQ-SF), and the Cognitive Emotion Regulation Questionnaire (CERQ). Collected data were analyzed using Pearson correlation test and Structural Equations Modeling (SEM) in AMOS software.

Results The results of SEM showed a direct significant path from early maladaptive schemas to cognitive emotional regulation, and from cognitive emotional regulation to spouse abuse. There were also significant indirect paths from the first, second, and third domains of early maladaptive schemas to spouse abuse mediated by negative cognitive emotion regulation strategies with a path coefficients of $0.13,0.16$, and 0.13 , respectively. The final structural model was a good-fitting model $\left(X^{2} / \mathrm{dF}=1.595\right.$, Root Mean Square Error of Approximation $=0.045$, Comparative Fit Index $=0.953$ ).

Conclusion The relationship between early maladaptive schemas and spouse abuse is not linear; it is mediated by cognitive emotion regulation.
\end{abstract}

\section{Extended Abstract}

\section{Introduction}

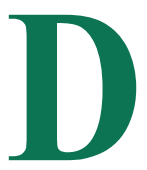

omestic violence refers to a type of aggression occurs within intimate relationships. It is also called "spouse abuse", "marital violence", "conjugal violence", "partner abuse" and etc. [1]. One of the best definitions for the domestic violence has been provided by Barnett et al. [2], as a pattern of aggressive and coercive behaviors in- cluding physical, sexual and psychological abuse, as well as economic coercion and threats against intimate partner. The most common domestic violence that occurs within intimate or family relationships is spouse abuse in husband-wife relationships [4]. The World Health Organization (WHO) defined the spouse abuse as any form of violence between current and former partners in intimate relationships at any time and place. This violence includes physical, sexual, emotional or financial abuse [5]. Spouse abuse is one of the most important types of violence and can lead to critical consequences such as severe dysfunction and even death [6]. Vari-

\section{* Corresponding Author:}

Hamid Kordestanchi Aslani

Address: Department of Clinical Psychology, Family Research Institute, Shahid Beheshti University, Tehran, Iran.

Tel: +98 (912) 3190718

E-mail: hkaslani@yahoo.com 
ous theories have explained spouse abuse, including feminist theory [9], attribution theory [10], source theory [11], culture of violent theory [12], sex-role theory [13], intergenerational transmission theory [14] and learned helplessness theory [15]. Some of these theories are rooted in sociology and others in psychology; both domains play an important role in explaining the spouse abuse. According to Strauss, spouse abuse cannot be explained by psychological, cultural or social factors alone; a combination of individual, cultural, and socioeconomic factors are involved in situations that cause spouse abuse [16].

In the field of psychology, researchers believe that individuals with violent behaviors have specific thought patterns that cause their anger to persist [17]. Young cites these patterns of thought as "early maladaptive schemas" which can make a person vulnerable to psychological problems [18]. Most maladaptive schemas are activated in adults with marital problems [21], and these maladaptive schemas play an important role in violent behaviors towards the spouse. Mason et al. [23] showed that the maladaptive schema of "failure" has a negative relationship with the sense of trust in spouses and the predictability of the spouse behavior. This scheme is directly related to abuse/mistrust in the spouse. Mason et al. [23] stated that the presence of early maladaptive schemas such as "emotional deprivation" or "defectiveness" is directly and negatively correlated with marital adjustment. Another study [23] showed that people with "unrelenting standards" schema have high unrealistic expectations of their spouse and get angry when these expectations are not met. Furthermore, their "negativity" schema causes them to be more self-controlled, instead of expressing intimacy to their spouse [24]. The presence of early maladaptive schemas such as social isolation/alienation, defectiveness/shame, unrelenting standards, and abuse/mistrust predicts that individuals with these schemas have been abused during childhood, and they will have violent behave in adulthood towards their spouse and children [25].

According to these studies, it can be concluded that early maladaptive schemas affect husband-wife relationships and are associated with spouse abuse. However, the more important question is how these early maladaptive schemas affect couples' relationship (spouse abuse)? It can be very useful to investigate the possible factors that play a mediating role in the relationship between early maladaptive schemas and spouse abuse. One of these factors examined in the present study is emotion regulation. It refers to the ability to perceive and modulate emotional experience or expression [26-28]. Emotion regulation is widely used in all aspects of life from the early stages of mental development; disturbance of emotions and their regulation can results in psychological damage $[29,30]$. According to Diagnostic and Statistical Manual of Mental Disorders, 4 th ed., more than $50 \%$ of the axis I disorders and $100 \%$ of personality disorders (axis II), involve some form of emotional dysregulation. For example, major depressive disorder is characterized by lack of a positive emotion or increased negative emotion; generalized anxiety disorder by exacerbated anxiety; disorganized schizophrenia by inappropriate emotional responses; and histrionic personality disorder by excessive excitement [32]. The inability to regulate emotions may be due to the early childhood schema that is not formed properly. In this regard, studies [35] have show a relationship between early maladaptive schemas and avoidance-oriented coping strategy, because an increase in the use of maladaptive schemas reduces the use of effective emotion regulation strategies; by reduced use of schemas, the use of appropriate emotion regulation strategies increases.

When couples are confronted with highly negative emotional events (e.g. anger caused by conflicts, despair, and frustration), they often turn to primitive interactions and survival skills. In this kind of interaction, couples repeatedly try to justify their behavior in ways such as humiliating or criticizing the spouse [37] or by expressing the negative characteristics of the spouse [38]. Emotion regulation allows couples to avoid these negative behaviors. It can help them reduce the arousal of their own and their spouse's emotions and achieve some sort of co-regulation [39-41]. These indicate the significant role of emotion regulation in reducing or increasing negative relationships between couples, and spouse abuse. Therefore, considering the relationship between early maladaptive schemas and spouse abuse, as well as the relationship between emotion regulation and spouse abuse, it is important to examine the mediating role of emotion regulation in the relationship of early maladaptive schemas with spouse abuse. Many studies have investigated the relationship of early maladaptive schemas and difficulties in emotion regulation separately with domestic violence, especially spouse abuse, but what the current study also identifies emotion regulation as a mediator of the relationship between them. From the fundamental aspect, this study provides some evidence for the relationship of studied variables with violence, especially against women. From the practical aspect, its results can be useful for those teachers, psychiatrists, psychologists, and family counselors to provide the ground for further empowerment to women victims of violence.

\section{Methods}

Samples were 324 married adults (men and women) who were selected using a convenience sampling technique. The sample size was determined based on the number of predictor variables. The questionnaires were distributed among them in different places including parks, shopping centers and cultural centers in five districts of Tehran (north, south, 
east, west and center). Participants answered the questionnaire after declaring consent to participate in the study.

Data collection tools were a demographic form surveying age, gender, occupation, education, and duration of marriage, the Young Schema Questionnaire- Short Form (YSQ-SF), the Cognitive Emotion Regulation Questionnaire (CERQ), and the Revised Conflict Tactics Scales (CTS-2). The YSQ-SF has 75 items adopted from the original 215item questionnaire by Young in 1998 to assess 15 early maladaptive schemas (5 items each). Each item is scored on a 6-point scale. A mean subscale score of $>2.5$ indicate that the schema is inefficient [45]. The standardization of this questionnaire for Iranian samples was performed by Ahi [48] who reported an internal consistency of $\alpha=0.97$ for female population and $\alpha=0.98$ for male population. The CERQ is a multidimensional questionnaire developed by Garnefski et al. in 2001 to identify cognitive emotion regulation strategies of individuals after experiencing negative life events or situations. It is a self-report tool with 36 items [50]. Hasani [52] for the Persian CERQ, reported a good reliability of 0.76-0.92 using Cronbach's alpha, a good test-retest reliability of $0.51-0.77$, an acceptable validity through principal component analysis using Varimax-rotation of factors with a correlation coefficient of $0.32-0.67$ between the subscales, and acceptable criterion validity [54]. The CTS-2, as one of the most useful tools for measuring interpersonal violence, was developed by Straus et al. [57] and revised in 1990 and 1996 [56]. The original version contains 78 items including two tests with duplicate items; 39 items describe aggressive behaviors (Perpetrator) and the other 39 items evaluate the spouse response to the aggressive behavior (Victim). The Persian version of CTS-2 has 52 items (26 items for each aggressor and victim form) and uses only three subscales of negotiation, psychological aggression, and physical assault. According to Panaghi et al. [61], the reliability of Persian CTS-2 using Cronbach's alpha coefficient for the negotiation subscale in both aggressor and victim forms was 0.77 ; for the psychological aggression subscale, it was reported 0.74 and 0.66 in aggressor and victim forms, respectively; and for the physical assault subscale, it was 0.81 and 0.86 , respectively.

\section{Results}

Based on the results in Table 1 which presents the demographic characteristics of the study participants, about 70\% $(n=226)$ of adults were female and about $30 \%(n=98)$ were male. As illustrated in Figure 1, after estimating the initial structural equation model, eliminating non-significant relationships, and modifying the model, the final structural equation model parameters were measured in AMOS V. 23

Table 1. Demographic characteristics of the study participants

\begin{tabular}{|c|c|c|}
\hline \multicolumn{2}{|c|}{ Characteristics } & \multirow{2}{*}{$\begin{array}{c}\text { No. (\%) } \\
226(69.8)\end{array}$} \\
\hline & Female & \\
\hline Gender & Male & $98(30.2)$ \\
\hline \multirow{4}{*}{ Age (year) } & $<30$ & $47(14.5)$ \\
\hline & $31-40$ & $173(53.4)$ \\
\hline & 1150 & 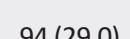 \\
\hline & $>51$ & $10(3.1)$ \\
\hline \multirow{6}{*}{ Duration of marriag } & $1-5$ & 31 (9.57) \\
\hline & $6-10$ & 71 (21.91) \\
\hline & $11-15$ & 96 (29.63) \\
\hline & $16-20$ & $56(17.28)$ \\
\hline & $\geq 21$ & 46 (14.20) \\
\hline & Not reported & $24(7.41)$ \\
\hline \multicolumn{2}{|c|}{ Total } & 324 (100) \\
\hline
\end{tabular}




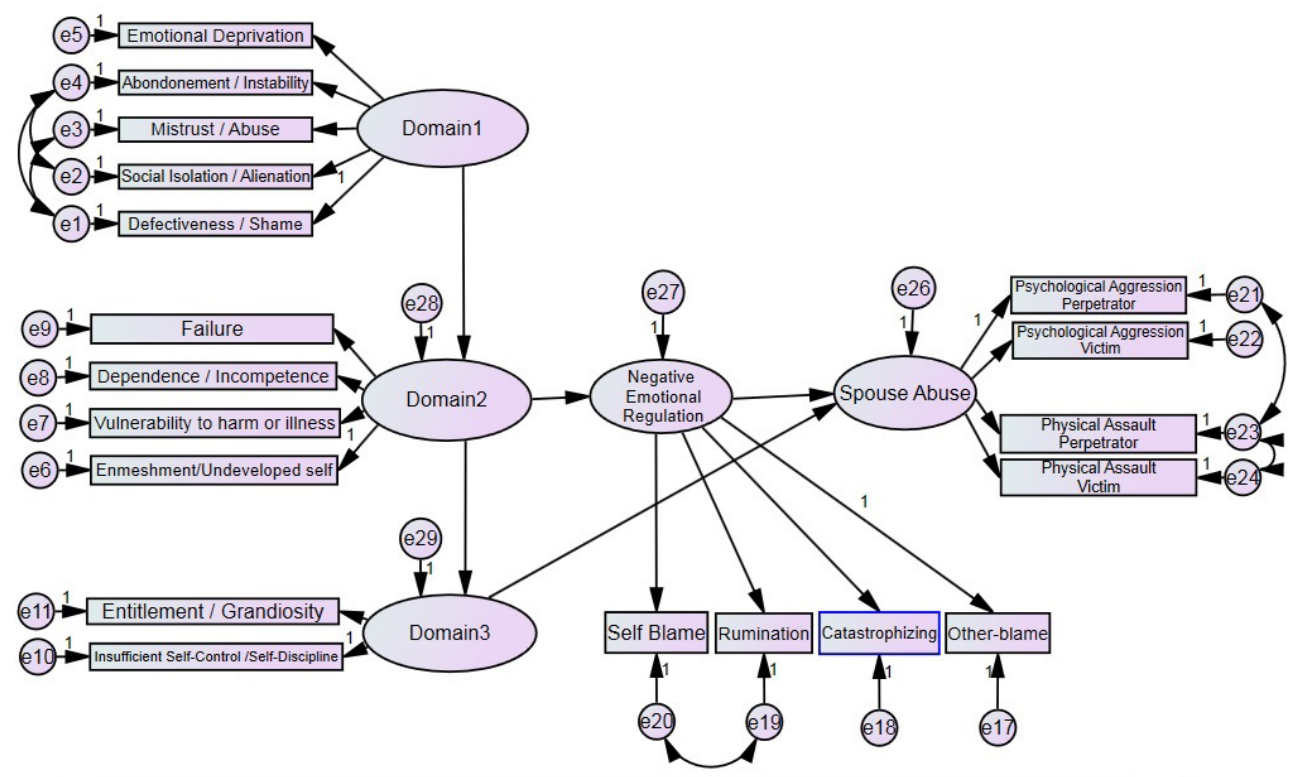

Iranian Journal of
PSYCHIATRY AND CUINICAL PSYCHOLOGY

Figure 1. Structural model of the mediating role of cognitive emotion regulation in relationship of early maladaptive schemas with spouse abuse

software using maximum likelihood estimation method. The values of the goodness of fit indices are presented in Table 2.

\section{A Model Goodness of Fit}

As shown in Table 2, the fit indices, in particular, the chisquared ratio to the degree of Freedom, is 1.595 (less than 3 criterion), Comparative Fit Index (CFI) is 0.9, and Normalized Fit Index (NFI) is 0.9, and the Root Mean Suare Error of Approximation (RMSEA) is 0.045 and the proposed model has a good fit.

Therefore, it can be deduced that the structural relationships between the early maladaptive schemas, cognitive emotion regulation and spouse abuse are meaningful in the measured model; so, cognitive emotion regulation can mediate the relationships between early maladaptive schemas and spouse abuse.

\section{Discussion and Conclusion}

The findings of this study showed that the domains of early maladaptive schemas directly and indirectly affect spouse abuse. In fact, the first domain of early maladaptive schemas (Disconnection/rejection) affected the spouse abuse once through the second domain and negative emotional regulation, and once through the second and third domains. The second domain affected the spouse abuse once after mediation by the negative emotional regulation and once through the third domain. Moreover, there was a direct link between the third domain and spouse abuse. These results are consistent with the findings of previous research [61-70]. Disconnection/Rejection domain is formed in response to dissatisfaction with the need for empathy and love. This domain is characterized by problems associated with attachment stability, and people with a high score in this domain lack a sense of acceptance, care, stability, and belonging in childhood.

Table 2. Goodness of fit indices for the study model

\begin{tabular}{cccccccc}
\hline Variables & $\mathbf{x}^{2} / \mathbf{d f}$ & RMSEA & GFI & AGFI & NFI & CFI & RFI \\
\hline Recommended value & $<3$ & $<0.08$ & $>0.9$ & $>0.85$ & $>0.9$ & $>0.9$ & $>0.9$ \\
Obtained value & 1.595 & 0.045 & 0.925 & 0.9 & 0.9 & 0.953 & 0.9 \\
\hline
\end{tabular}


Therefore, this domain is considered as the most important domain due to its association with various psychological problems [72-74]. This is in line with our findings reporting that the first schema domain has a higher effect compared to other domains.

According to another finding of the present study, negative emotion regulation plays as a mediator in the relationship of early maladaptive schemas with spouse abuse. It can be stated that early maladaptive schemas are one of the contributing factors in emotional regulation problems. In fact, early maladaptive schemas as individual traits can trigger or exacerbate emotional disorders such as anxiety, depression, and anger. Individuals with early maladaptive schemas are unable to manage their emotions; therefore, the early maladaptive schemas can increase the likelihood of spouse abuse by exacerbating negative emotions and leading to emotional disorders. Difficulty in emotion regulation further causes the use of immature defense mechanisms to deal with negative emotions and results in increased spouse abuse [77].

Another result of this study was a direct relationship between the third domain of early maladaptive schema (Impaired Limits) and spouse abuse. Deficiency in the third domain indicated internal limits and impaired sense of responsibility towards others or orientation towards long-term goals that can lead to problems in relationships or cooperation with others, especially the spouse. For example, a person with entitlement/grandiosity schema believes that $\mathrm{s} / \mathrm{he}$ is superior to the others and has special rights and is not obligated to respect the principle of reciprocity which is an important factor in normal marital relationships. Such people, in order to gain power or control over others, have an excessive focus on supremacy and dominating their spouse, which in turn causes spouse abuse. Overall, the findings of this study revealed the mediating role of cognitive emotional regulation in the relationship of early maladaptive schemas with spouse abuse.

Cognitive emotion regulation (especially negative emotion regulation) explains the relationship of the early maladaptive schemas (especially the first and second domains) with the spouse abuse. There is a direct relationship between the third domain of early maladaptive schemas and spouse abuse. The study model presented showed the greater effect of negative strategies of emotion regulation and their maladaptive and inappropriate use during spouse abuse compared with to a positive and adaptive strategies.

\section{Ethical Considerations}

\section{Compliance with ethical guidelines}

The researcher and assistants have explained all stages of the research. The participants completed the questionnaires voluntarily.

-The questionnaires designed with a code with no name and surname; thus the participants remain anonymous.

- It is explained that the data in the questionnaire will be confidential. The researcher and the assistants re-emphasized the confidentiality of the questionnaires and their non-use by another person, institution, or authority.

-This research was approved on 18/6/2017 (Code: 37946 ) in terms of observing the principles of ethics with no public moral prohibition.

All ethical principles were observed in this study. All participants signed an informed consent form and were assured of the confidentiality of their information (Ethical approval Code: 37946).

\section{Funding}

This article was extracted from the MA. thesis of the second author at the Department of Clinical Psychology, Family Research Institute, Shahid Beheshti University, Tehran.

\section{Authors contributions}

All authors equally contributed to preparing this article.

\section{Conflicts of interest}

The authors declare no conflict of interest. 


\title{
نقش ميانجى تنظيم هيجان شناختى در رابطه طرحوارههاي ناساز كار اوليه با همسرآزارى
}

\author{
على زادمحمدى' هـ "خميد كردستانجى اصلانى'
}

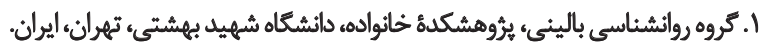

\begin{abstract}
حكيد

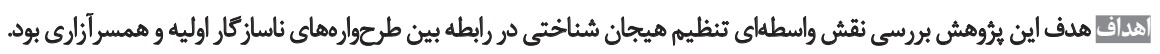

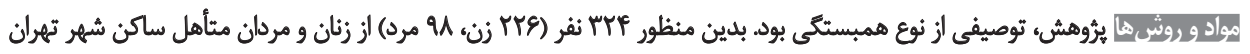

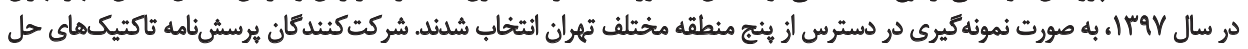

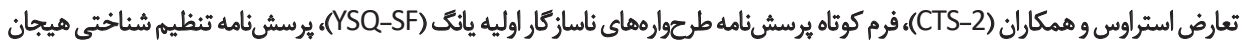

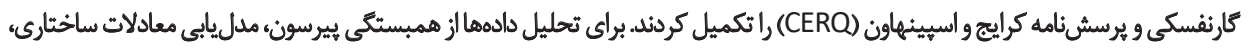

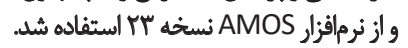

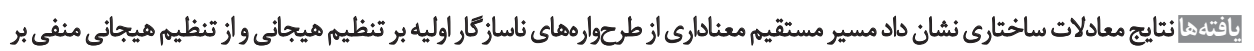

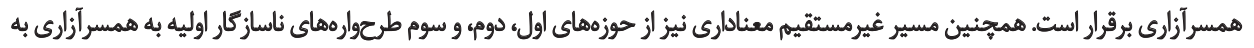

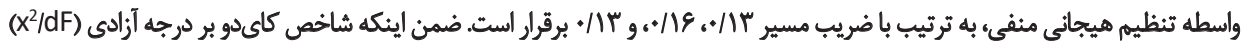

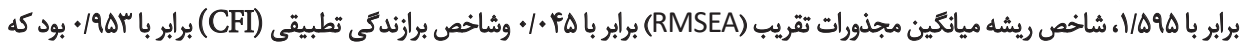
تشانكر برازئنسى خوب مدل أست.

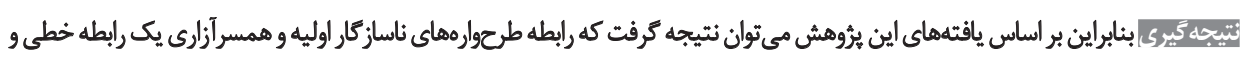
ساده نيست و تنظيم هيجان در اين رابطه نقش واسطرائ دارد.
\end{abstract}

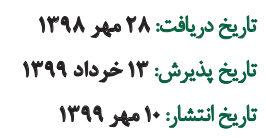

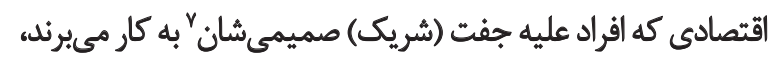
مقدمه

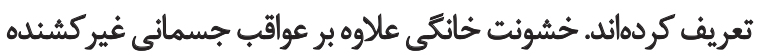

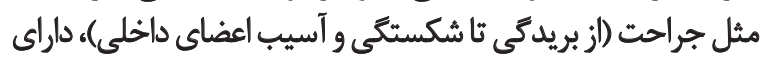

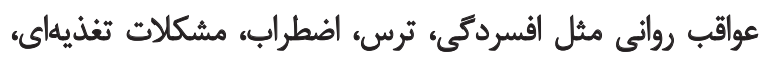

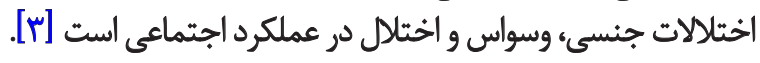
خشونت خانكى مي تواند در هر رابطه خودمانى و صميمى يا روابط إنى

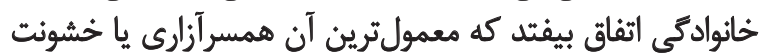

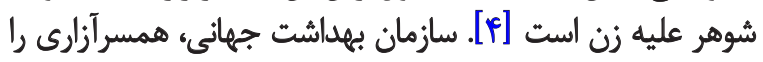

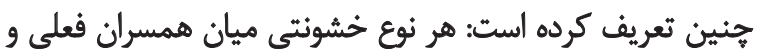

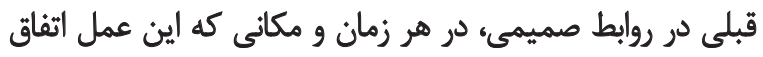

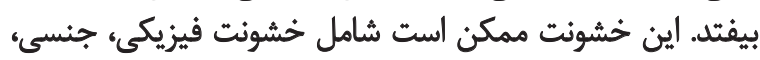

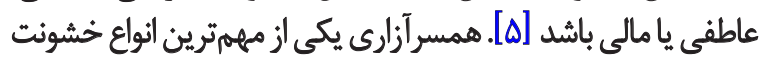

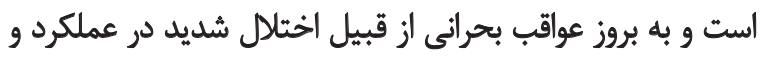

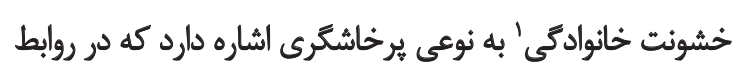

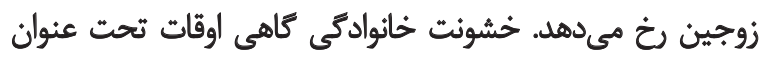

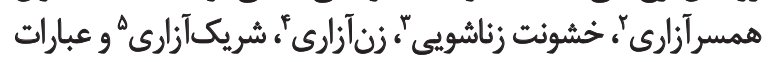
ديكر توصيف شده است [1]. يكي أز بهترين تعاريف خدارئ خشونت

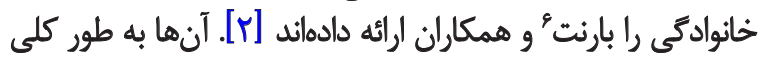

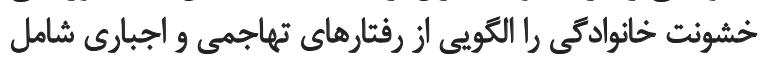

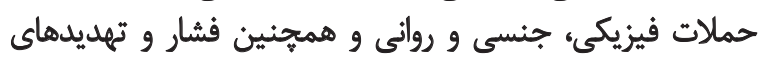

\footnotetext{
1. Domestic violence

2. Spouse abuse

3. Marital violence

4. Conjugal violence

5. Partner abuse

6. Barnett, Miller, Perrin
}

تنظيم هيجان شناختي، طرحوارههاى ناساز كار اوليه،

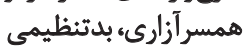
هيجانى

\section{-}

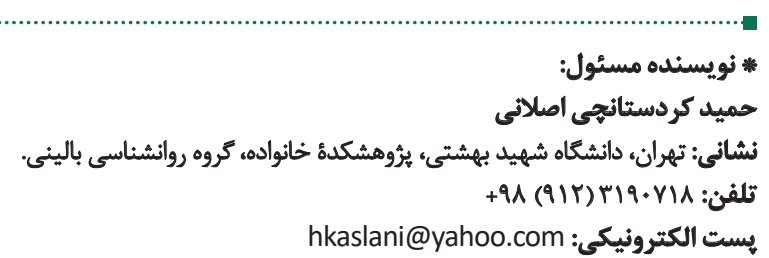




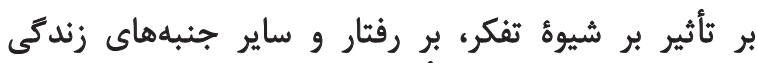

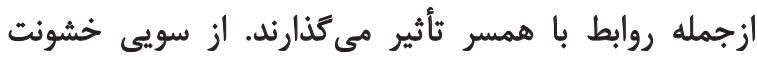

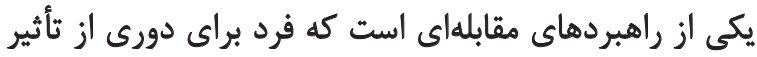

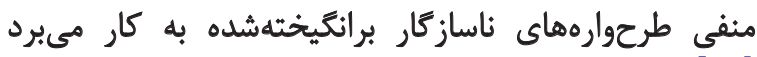

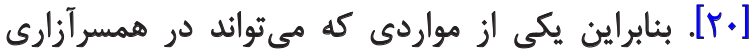

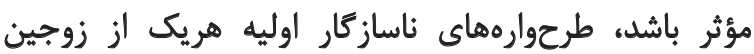

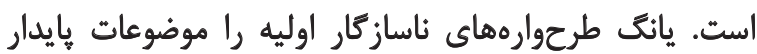

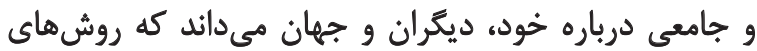

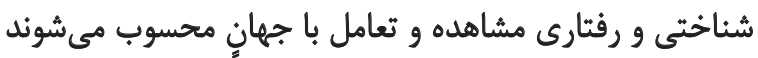

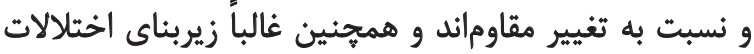

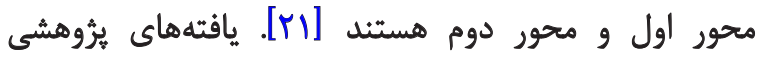

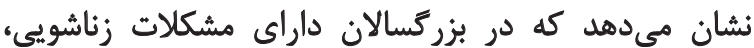

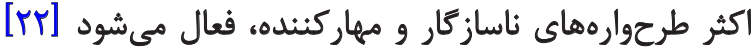

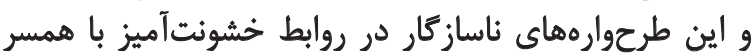

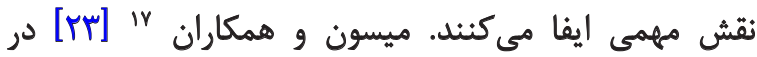

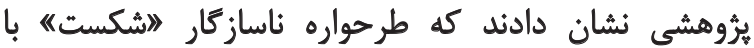

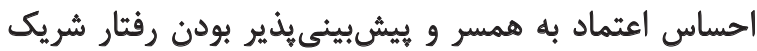

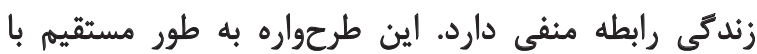

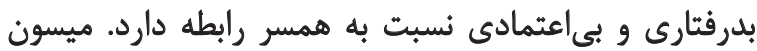

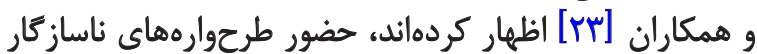

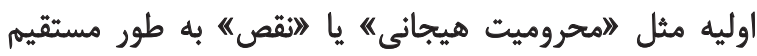

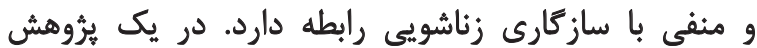

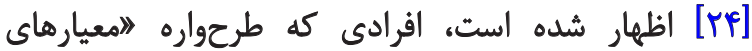

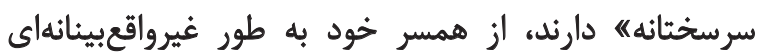

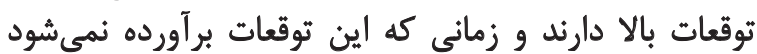

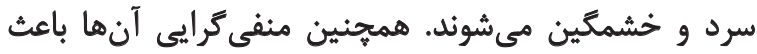

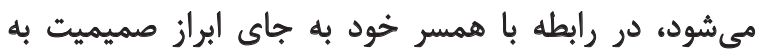

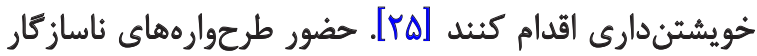

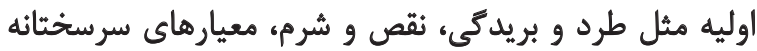

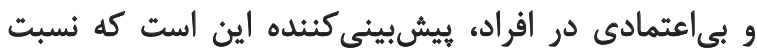

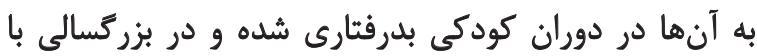

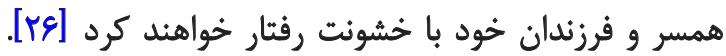
بر اساس اين يافتهها و موارد بسيار ديكر ميتوان نتيجه كرفت

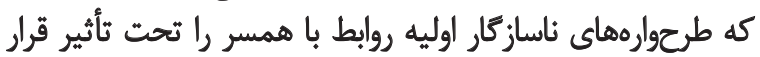

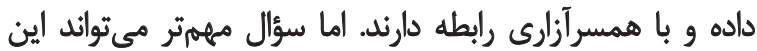

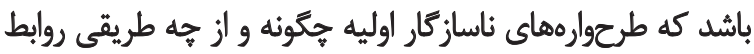

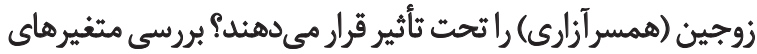

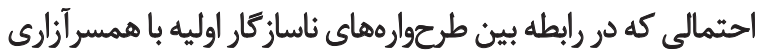

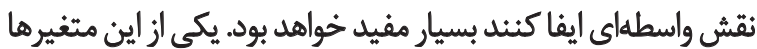
كه در اين يرؤهش به آن يرداخته مي بشود، تنظيم هيجاني است.

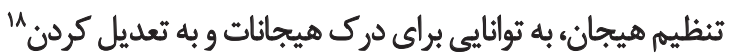

17. Mason

18. Modulate
حتى مرى منجر مىشود [ع] [.

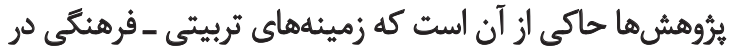

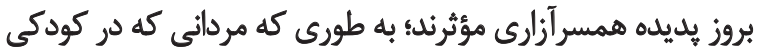

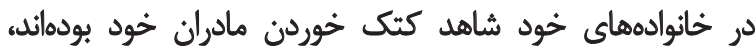

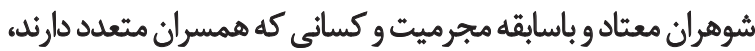

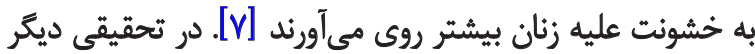

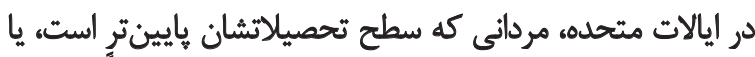

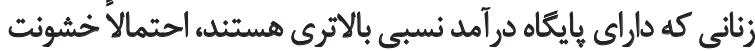

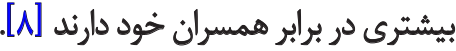

نظريههاي مختلفى براى تبيين همسر آزارى وجود دارد از جمله

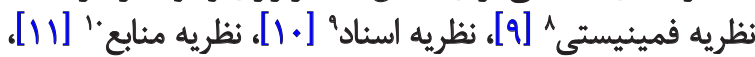

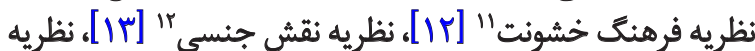

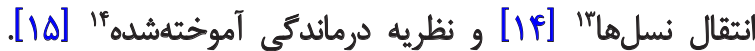

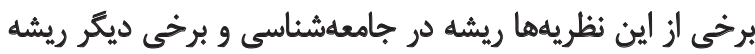

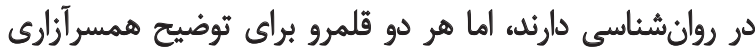

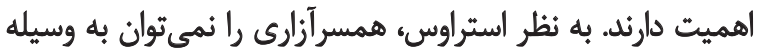

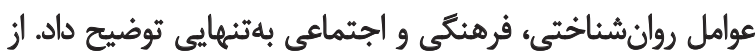

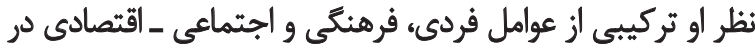

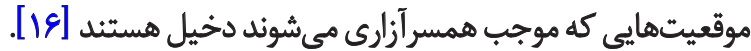

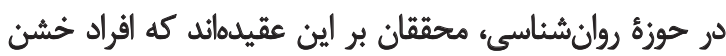

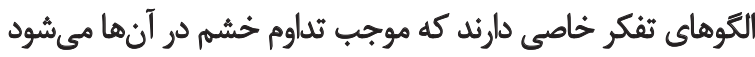

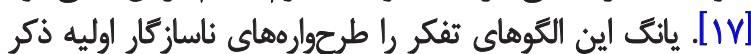

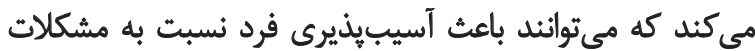

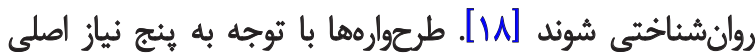

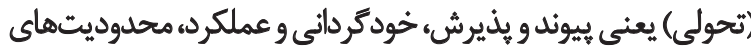

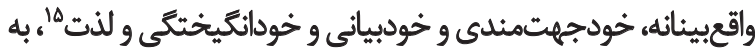

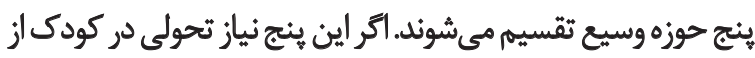

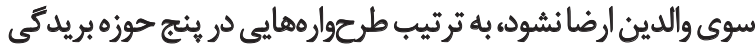

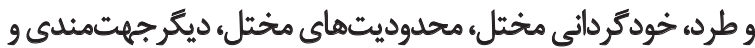

كوشبهزنتى بيشازحد و بازمارى ها، به وجود مى آيند [19].

بر اساس ديدگاه يانكَ طرحوارههاى ناسازگتار اوليه علاوه

8. Feminist theory

9. Attribution theory

10. Sources theory

11. Culture of Violence theory

12. Sex-Role theory

13. The Intergenerational Transmission theory

14. Learned Helplessness theory

15. Connection \& Acceptance, Autonomy \& Performance, Realistic Limits, Inner-directedness, Self-expression \& Spontaniety \& Pleasure

16. Disconnection \& Rejection, Impaired Autonomy \& Performance, Impaired Limits, Other-directedness, Overvigilance \& Inhibition 


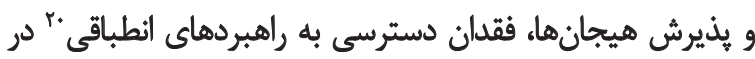

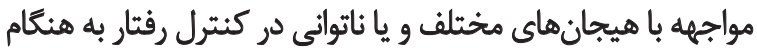

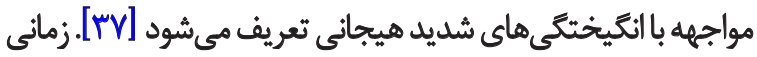

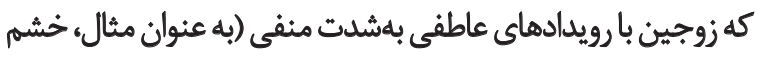

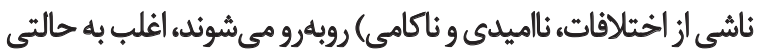

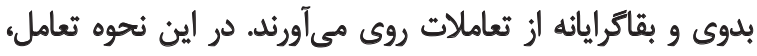

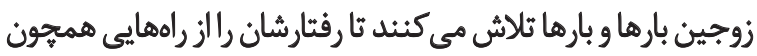

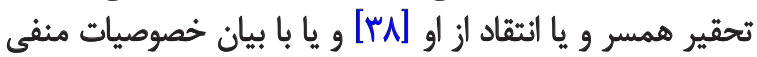

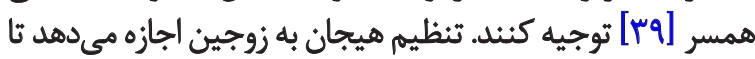

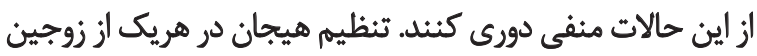

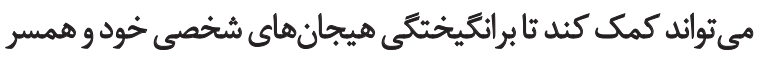

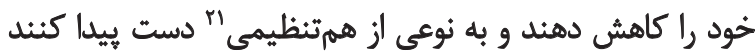

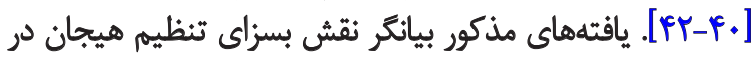

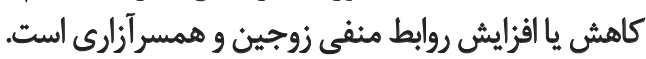

بنابراين با توجه به رابطه بين طرحوارههاى ناسازكار اوليه و ورئ

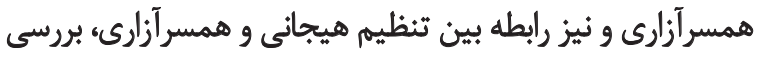

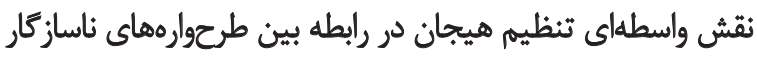

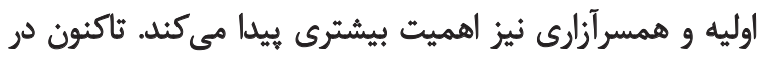

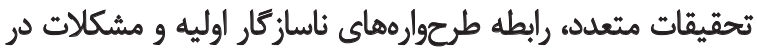

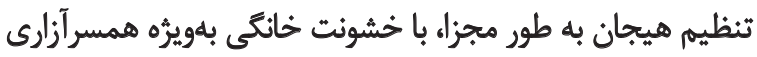

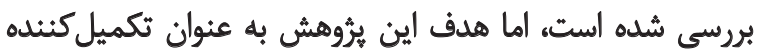

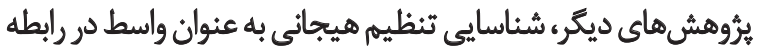

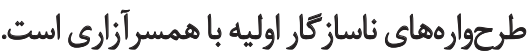

إثروهش حاضر از دو بُعد بنيادى و كاربردى حائز اهميث است:

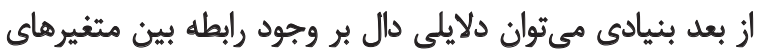

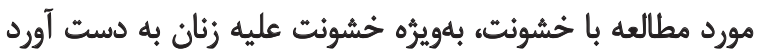

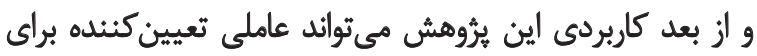

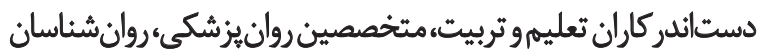

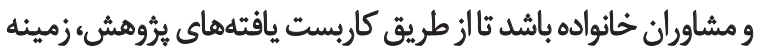

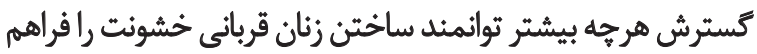

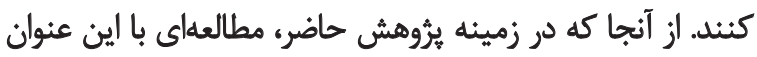

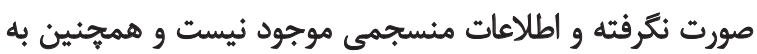

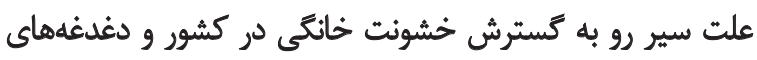

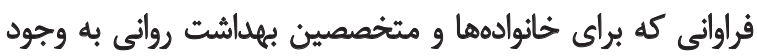

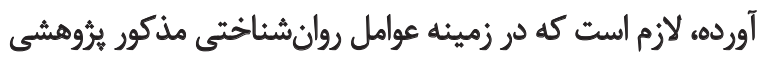
علمى، هدفمند و كاربردى به عمل آيد.

ووش - م

روش يُروهش، توصيفى از نوع همبستكى بود يس از از تنظيم

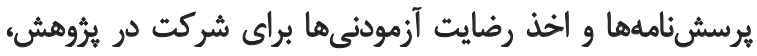

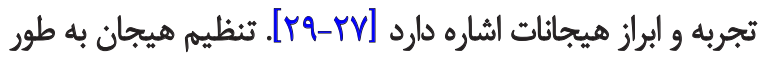

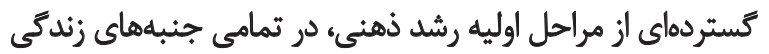

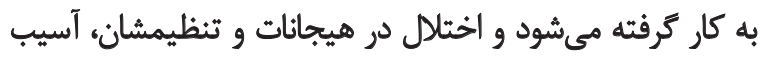

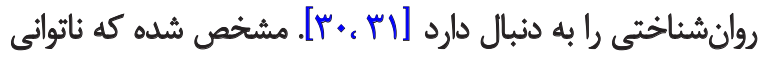

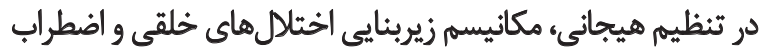

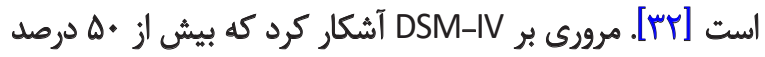

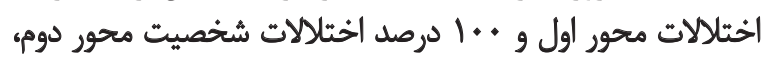

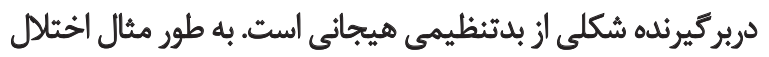

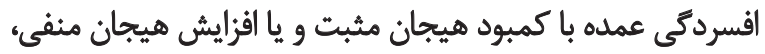

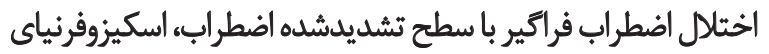

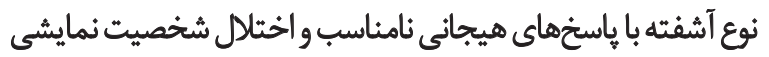

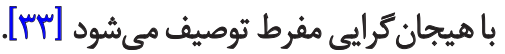

مديريت و تنظيم هيجانات بر مبناى فرايندهاى متعدد و

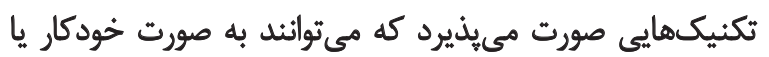

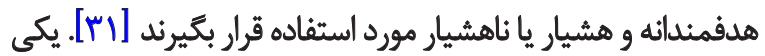

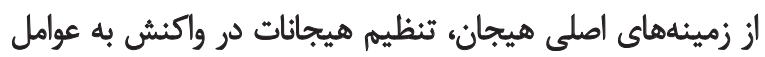

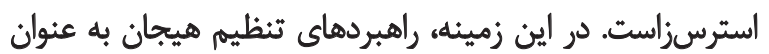

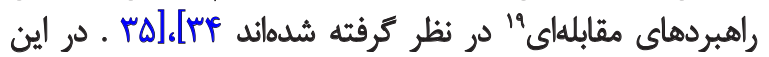

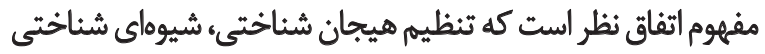

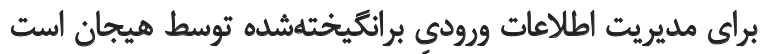

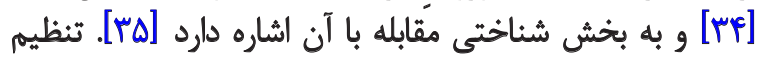

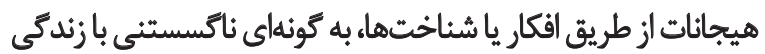

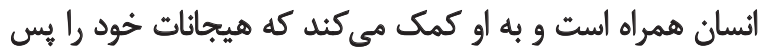

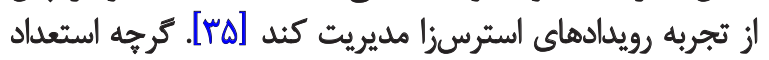

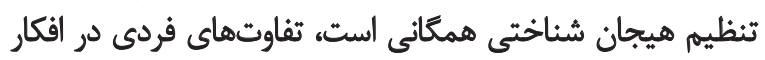

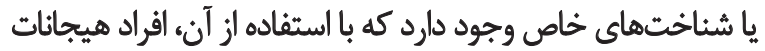

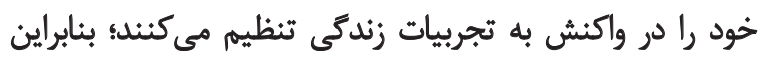

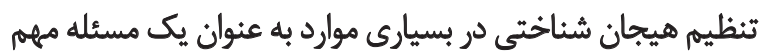

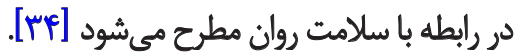

عدم توانايى در تنظيم هيجان، ممكن است ناشى ازٔ طرحواره اوليه

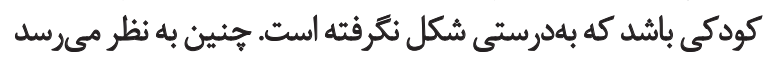

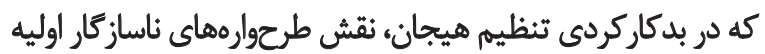

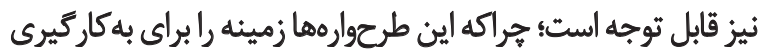

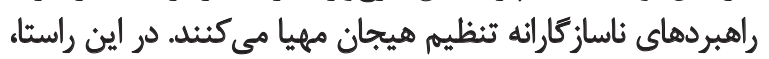

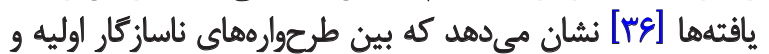

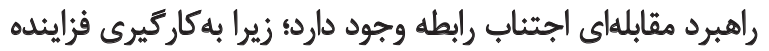

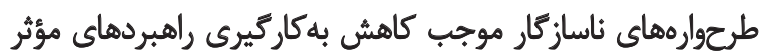

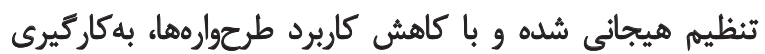
راهبردهاى مناسب تنظيم هيجانى افزايش مي يابد كاريد. دشوارى تنظيم هيجان از طريق بروز مشكلاتى در آكاهى، درى مئى 
نمرهكذارى هي شود و هر ينج سؤال يك طرحواره را ميسنجل.

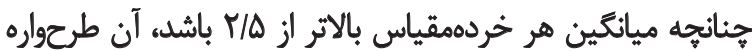

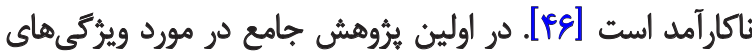

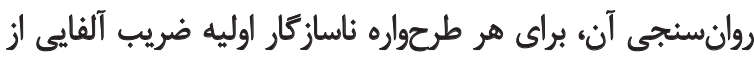

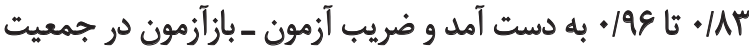

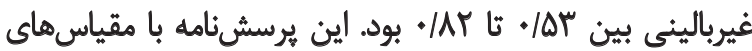

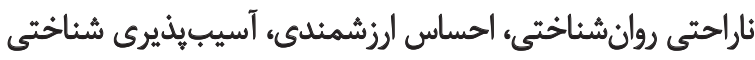

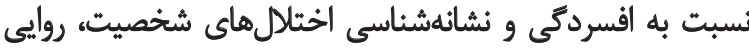

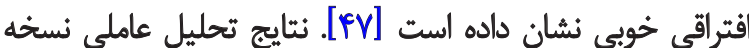

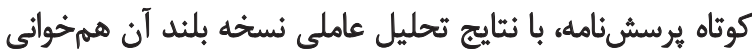

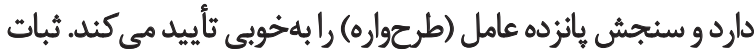

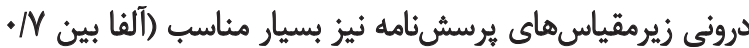

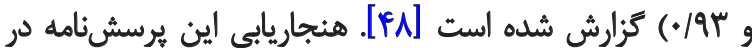

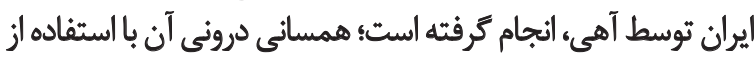

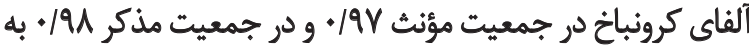

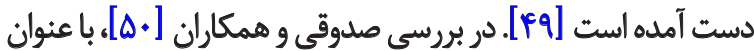

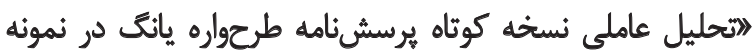

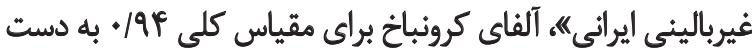

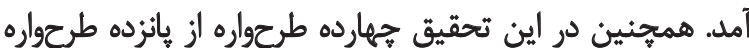

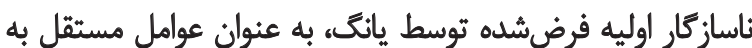

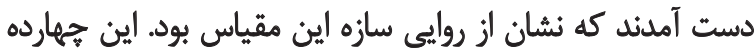

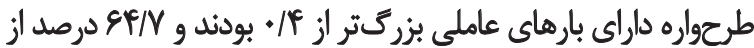

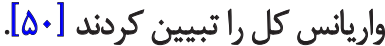

\section{يرسش نامه راهبردهاى تنظيم شناختى هيجان (CERQ)}

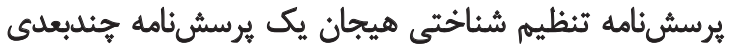

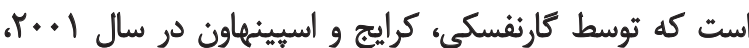

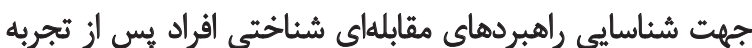

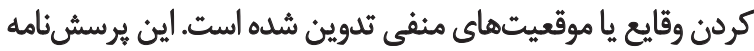

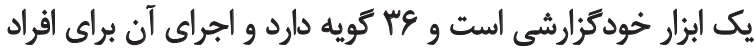

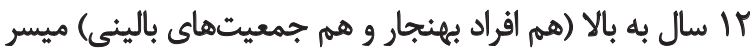

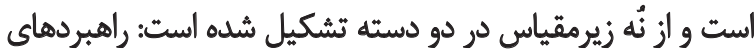
منفى تنظيم هيجان (جهار زيرمقياس)، و راهبردهاى مثبت دئ تنظيم هيجان (ينج زيرمقياس) [01]

هر زيرمقياس شامل جهار كويه است. نمره كل هريك از

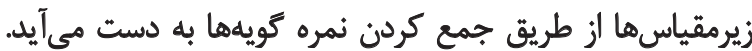

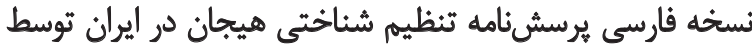

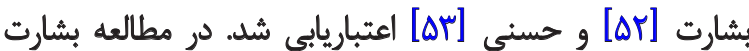

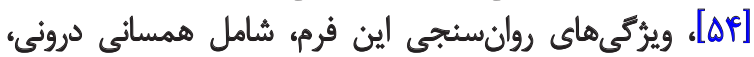

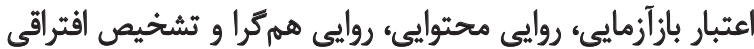

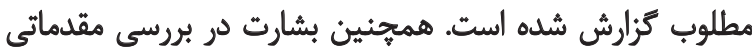

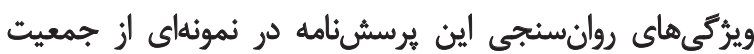

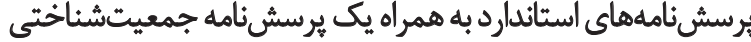

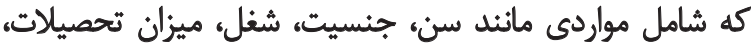

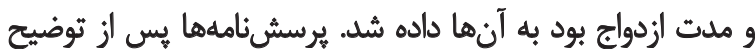

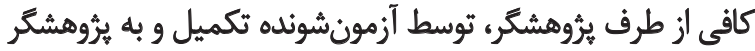

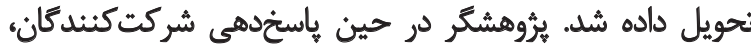

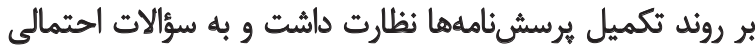

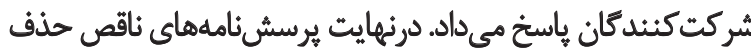

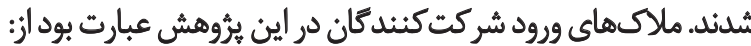

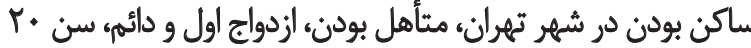

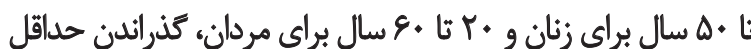

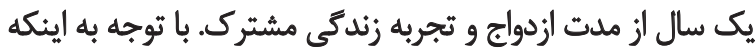

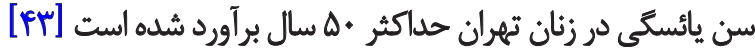

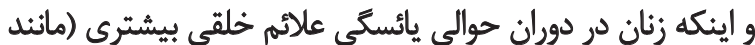

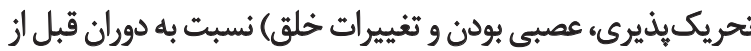

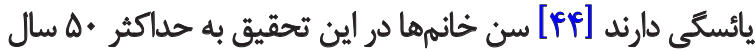

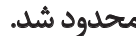
معيارهاى خروج از يرؤهش نيز شامل سابقه بيمارى روانيزشكىي،

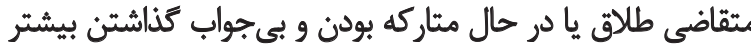

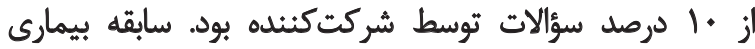

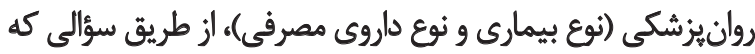

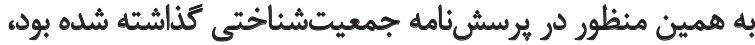

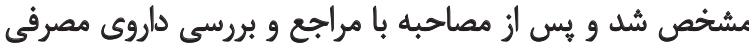
احتمالى در مورد حضور يا عدم حضور شركت بكنئده تصميمكيرى باري

شد.

جامعه، نمونه و روشُ نمونهكَيرى

جامعه آمارى شامل تمامى زنان و مردان مثأهل ساكن شهر

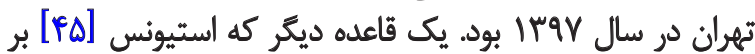

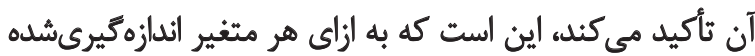

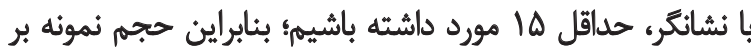

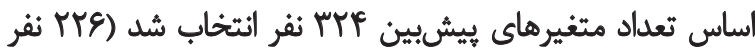

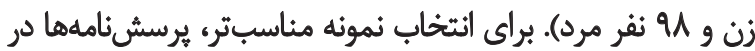

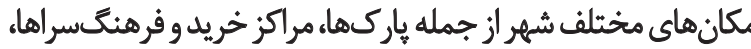

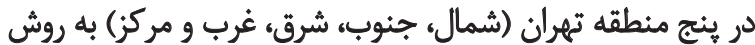

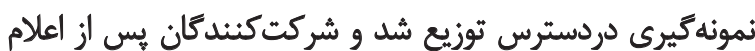

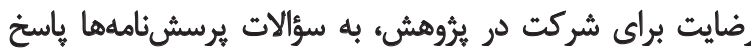
هادند.

\section{فرم كوتاه يرسشنامه طرحواره يانتى (YSQ-SF)}

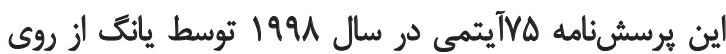

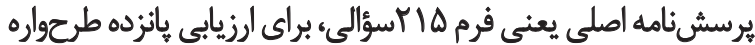

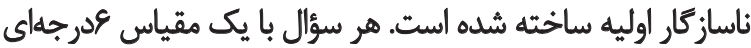

22. Young Schema Questionnaire-Short Form 
در نمونهاى از دانشجويان، مورد بررسى قرار كرفت؛ آنها ضريب بريب

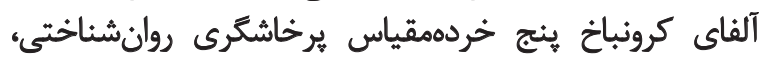

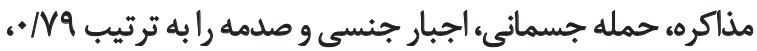

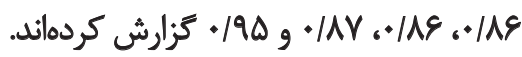

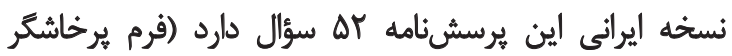

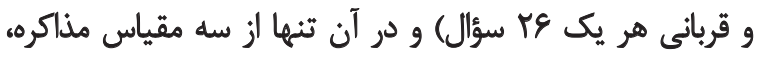

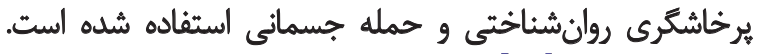

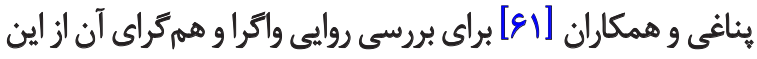

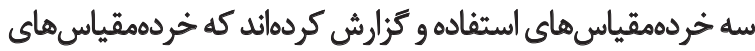

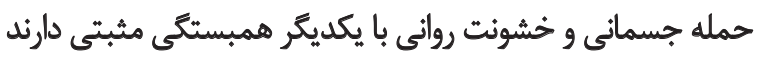

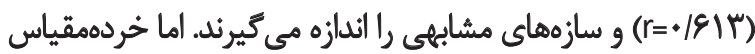

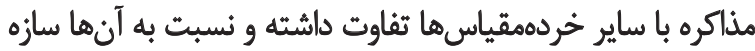

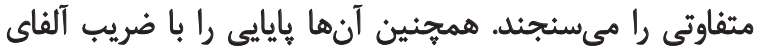

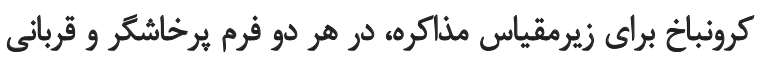

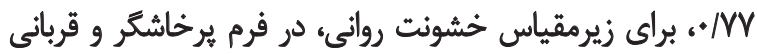

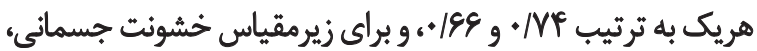

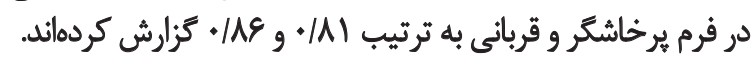

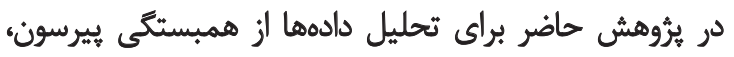

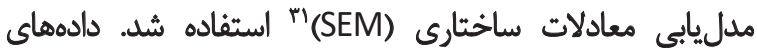

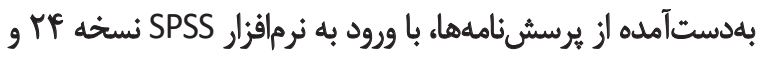

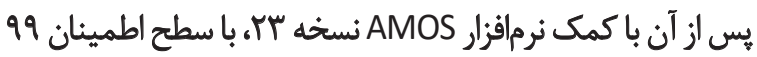
درصد مورد تجزيه و تحليل قرار كرفتند.

يافتهها

مشخصات جمعيتشناختى نمونه در جدول شماره ا ارئه شده

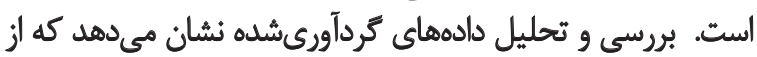

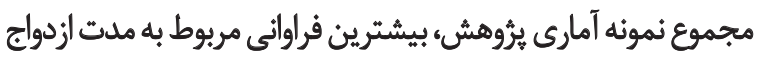

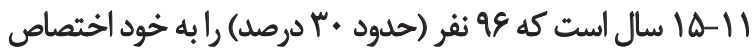

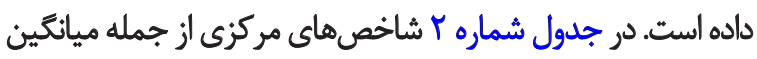

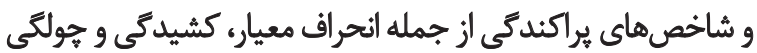

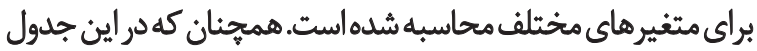

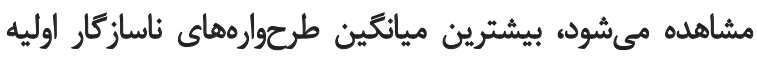

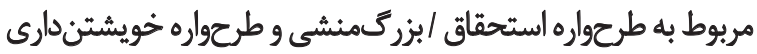

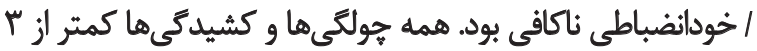

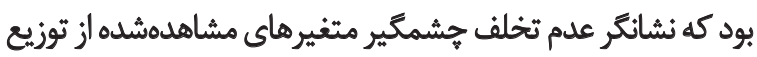

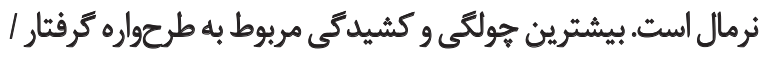

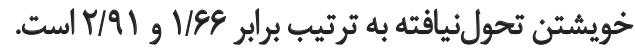
در مرحله بعد، ضريب همبستئى متغير هاى تحت مطالعه محاسبه

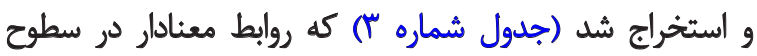

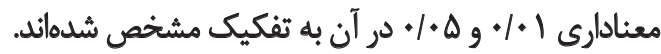

31. Structural Equation Modeling

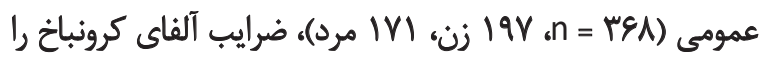

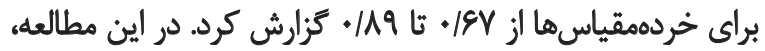

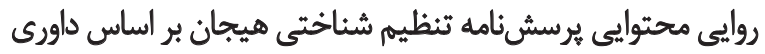

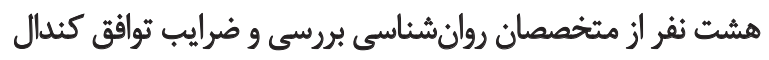

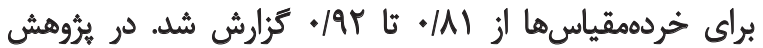

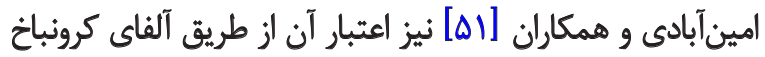

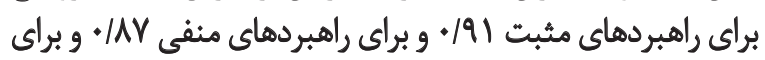

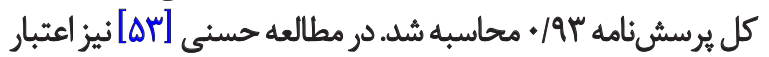

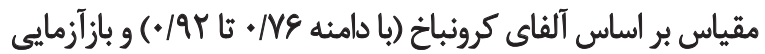

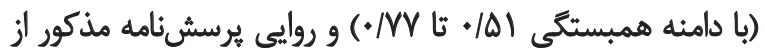

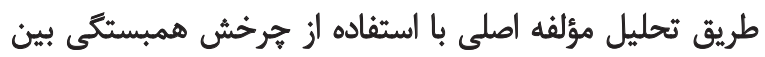

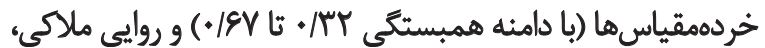
مطلوب كزارش شده است [هاس].

$$
\text { برسش ئاهة تاكتيكهاي حل تعارض }
$$

اين برسشنامه كه يكى از كاربردىترين ابزارهاى سنجش

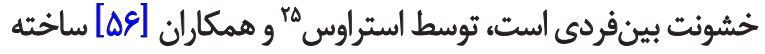

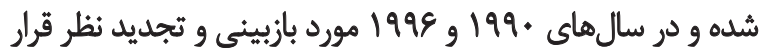

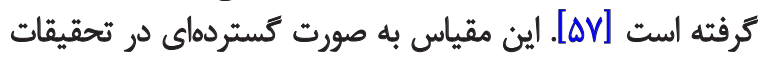
و در كشورهاى مختلف مورد استفاده قرار كرفته و تا سال 1999

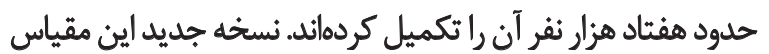

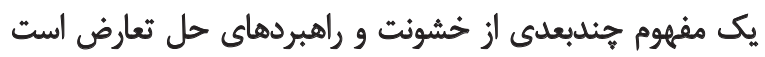

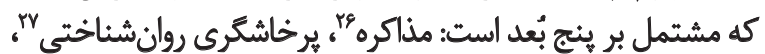

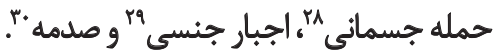

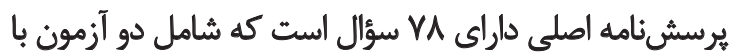

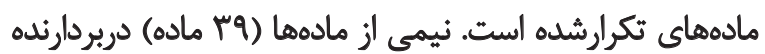

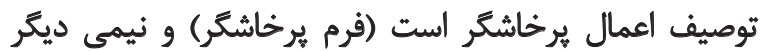

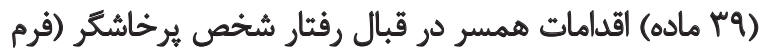

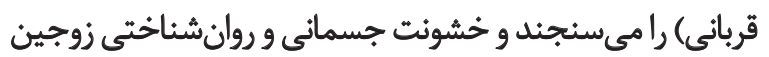

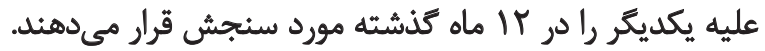

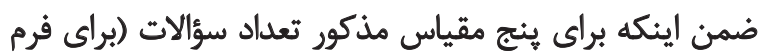

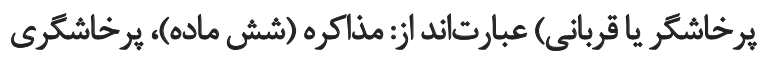

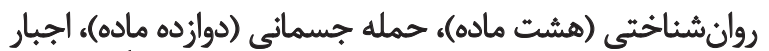

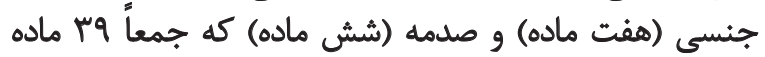

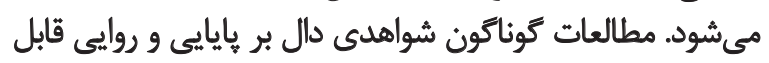

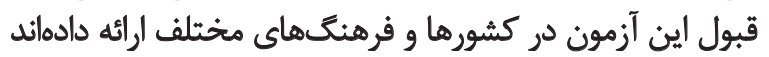

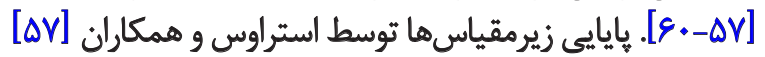

24. Conflict Tactics Scales (Revised) (CTS-2)

25. Straus

26. Negotiation

27. Psychological aggression

28. Physical assault

29. Sexual coercion

30. Injury 


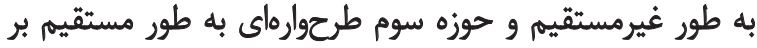

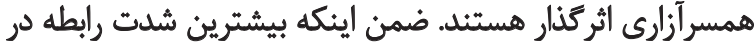

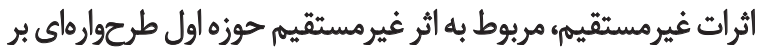

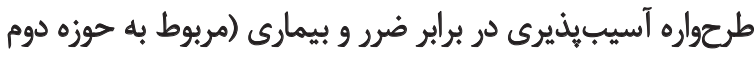

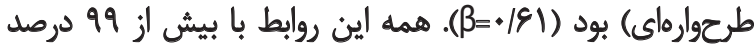
الطمينان مثبت و معنادار هستند.

$$
\text { برازش مدل }
$$

همان گونه كه در جدول شماره V مشاهده مى شوده، شاخصهاى

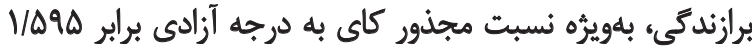

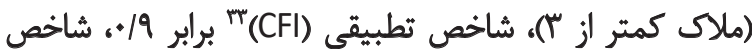

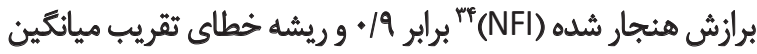

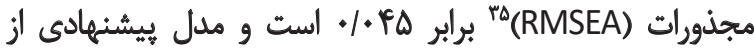

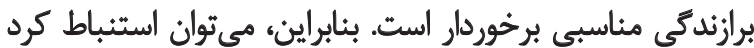

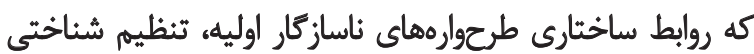

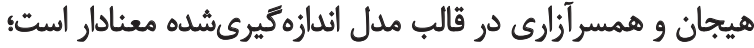

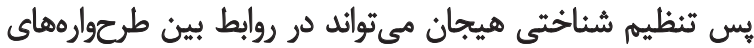

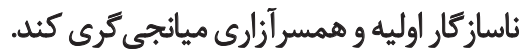

32. Goodness of Fit

33. Comparative Fit Index

34. Normed Fit Index

35. Root Mean Square Error of Approximation
بعد از بررسى مفروضات مدليابي معادلات ساختارى، شامل

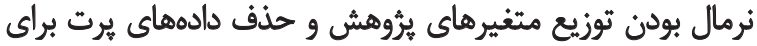

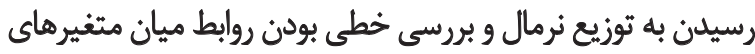

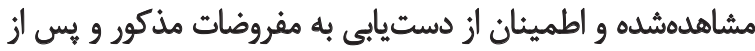

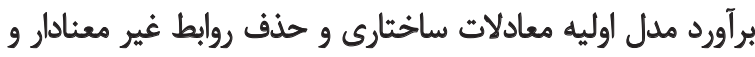

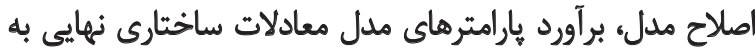

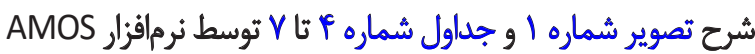

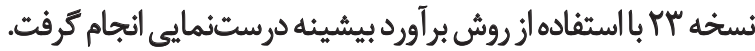

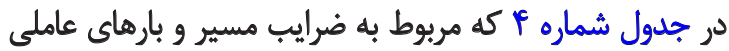

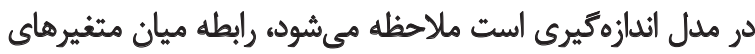

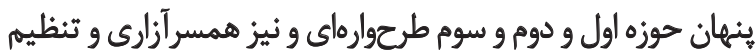

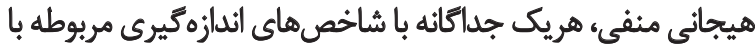
بيش از 99 درصد اطمينان مثبت و معنادار است. در جدول شماره ه مشاهده مىشود كه بيشترين شدت رابطه،

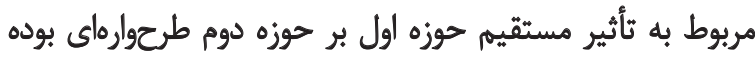

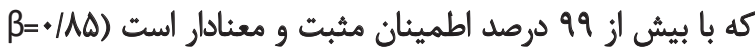

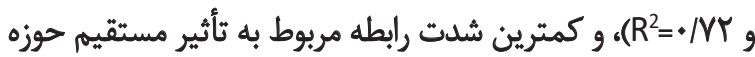

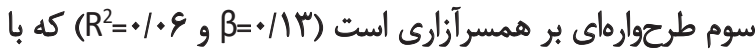
بيش از هو درصد اطمينان مثبت و معنادار است. جدول شماره \& مربوط به ضرايب مسير مستقيم و اثرات كلى ائى

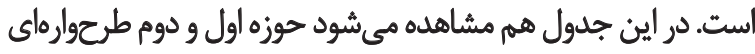

جدول ا. وضعيت افراد هاسخدهنده از نظظر عوامل جمعيتشناختي

\begin{tabular}{|c|c|c|}
\hline فراوانى (درصد) & & \\
\hline $\operatorname{Mg}(\xi 9 / 1)$ & نن & \multirow{2}{*}{ جنسيت } \\
\hline$Q 4(r+/ r)$ & مرد & \\
\hline $\operatorname{Pr}(\mid N / \Delta)$ & $<r$. & \multirow{4}{*}{ سن س } \\
\hline $\ln (\Delta r / f)$ & $m-r$. & \\
\hline$q F(r q / *)$ & $P 1-\Delta$. & \\
\hline $1 \cdot(N / M)$ & $>\Delta 1$ & \\
\hline$r(q / \Delta V)$ & $1-\Phi$ & \multirow{6}{*}{ مدت ازدواج } \\
\hline$V(T / 9))$ & $8-1$. & \\
\hline$q(Y Q / 9 \%)$ & $11-10$ & \\
\hline$\Delta E(I V / T N)$ & $\mid s-r_{*}$ & \\
\hline$F \in(I F / r \cdot)$ & $\geq r$ & \\
\hline$r e(V / P I)$ & كزارش تشده & \\
\hline \multicolumn{2}{|c|}{$\operatorname{Mrf}(1 \cdot)}$. & كل \\
\hline
\end{tabular}




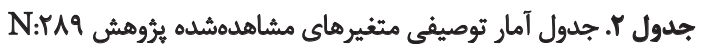

\begin{tabular}{|c|c|c|c|c|c|}
\hline بيشيترين مقدار & كمترين مقدار & كشيدكّى & هولّىى & ميانغين Iانحراق معيار & مثتير \\
\hline$\varphi / \Delta$ & $1 /$ & .190 & - AY & r/FA土./AM & ملامت خويش \\
\hline$\Delta /$. & 1 & $-\cdot / r 8$ & $\cdot / \mu$ & $r / M \Psi \pm \cdot N \Delta$ & بذيّش \\
\hline$ه /$ & $\mathbb{H}$ & -.18 & .1 .8 & M/IF士./AT & نشخْولراركرى \\
\hline$\Delta /$. & $1 \%$ &.$- / 9$ & $\cdot \pi$ & $ץ / \bullet 1 \pm \cdot / 9 q$ & تمركز هجدد همبت \\
\hline$\Delta / \cdot$ & $1 / 0$ & $-+M$ & $-* / \pi r$ & $M / 8 \cdot \pm \cdot / N$ & تمركز مجدد بر برئامهريزى \\
\hline$\Delta / \cdot$ & $1 / r$ & $-\cdot / W$ & $-\cdot 1 \cdot 1$ & $r / r \Delta \pm . / q r$ & ازوزيابى مجلد مثبت \\
\hline$\varphi / A$ & $1 / \pi$ & $-\cdot M r$ & .1 .9 & $r / l \cdot \pm \cdot M$ & ديدكاه كيرى \\
\hline$r / \Lambda$ & $1 \%$ &.$/ T \Delta$ & -ND & $r / N T \pm \cdot N E$ & فاجعdسازي \\
\hline$r / \Delta$ & $1 /$ & V/AV & $1 / \cdot 1$ & $r / M A \pm / Q V$ & ملامت ديكران \\
\hline$\Delta / \varphi^{\prime}$ & $1 / *$ &.$|\Delta|$ &.$/ 4$ & $r / \cdot v \pm \cdot / u$ & محروميت هيجانى \\
\hline$\Delta / 8$. & $1 / *$ & $+1+r$ & $\cdot \mid N E$ & $\Upsilon / \Upsilon \sim \wedge \pm V / \bullet \wedge$ & رهاشدكى /بىثباتى \\
\hline$\Delta / r$. & $1 / \cdots$ & $\cdot M$ & .199 & $r / .9 \pm \cdot / 19$ & بىاعتمادى / بلدرثتارى \\
\hline$\%$ & $1 / \cdots$ & $T / W$ & $V / \Delta H$ & $1 / R V \pm \cdot(\Delta)$ & انزواي اجتماعي / ييكانكى \\
\hline $1 / 99$ & $1 / \cdots$ & $r / M q$ & $1 / 8 T$ & $1 / 1 \pm \pm \cdot / \Lambda \Delta$ & نقص/شرم \\
\hline 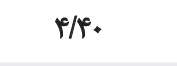 & $1 / \cdots$ & I/AP & $1 / x$ & $1 / 8 \cdot \pm \cdot / 8 V$ & شكست \\
\hline$r / .+$ & $1 /$. & T/R & $1 / P D$ & $1 / 19 \pm . / 19$ & وابستكى / بي كفايتى \\
\hline$r / A$ & $1 /$. & $1 / \Delta E$ & $1 / \% q$ & $1 / 1 / \pm \cdot / 19$ & أسيبذئيرى در برابر ضرر و ييمارى \\
\hline P/RA & $1 / \cdot$ & $r / 91$ & $1 / 89$ & I/Fa土./er & كرفتار / خويشتن تحولنيافته \\
\hline $81 .+$ & $1 / *$ & $\cdot \pi$ & +189 & r/\&E士 $/ \mathrm{Ru}$ & استحقاق / بزركمنشى \\
\hline$\varepsilon / \ldots$ & $1 * *$ & $1 / 79$ &.$/ 99$ & $r / \Psi \cdot \pm \cdot / A V$ & خويشتندارى/خودانضباطى ناكافى \\
\hline $\mathbb{M}$ &.$/ \%$ & $-\cdot N 8$ & 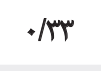 & $\cdot / M V \pm \cdot / r$ & خشونت روانى - يرخاشكر \\
\hline $1 /$. &.$\%$ &.$/ T 8$ &.$M$ & $\cdot$ /MA土./M & خشويتت روائى - قربائى \\
\hline 19. & $\%$ & l/pe & $V / \Delta \Delta$ & $\cdot / M \pm \cdot / r$ & خشويت جسمانى - برخاشكر \\
\hline 191 & $\%$ &.$/ N F$ & D/TE & $\cdot M A \pm \cdot / M V$ & خشونت جسمانى ـ قربانى \\
\hline
\end{tabular}

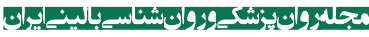

هيجانى منفى و يكبار از طريق حوزه دوم و حوزه سوم طرحوارهاى

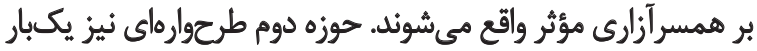

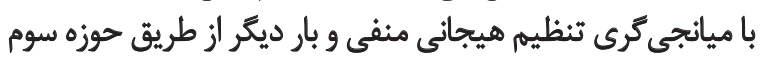

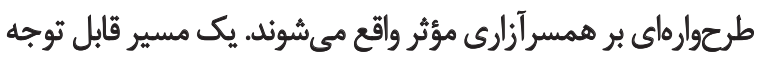

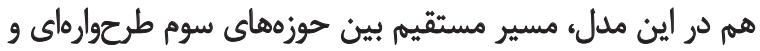

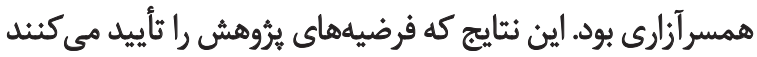

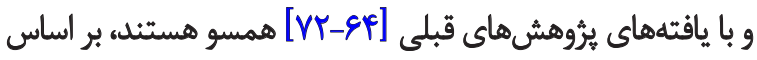
جندين احتمال به شرح زير تبيين مئشوند: 
文

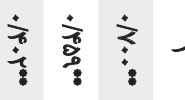

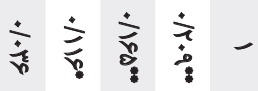

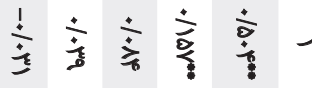

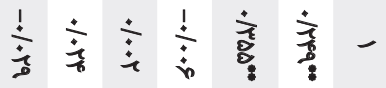

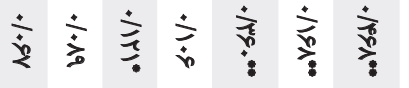

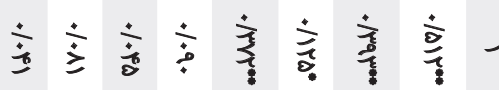

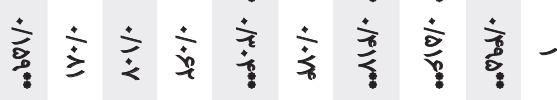

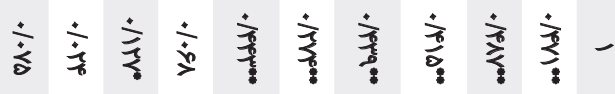

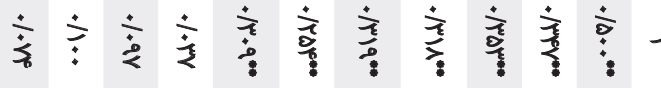

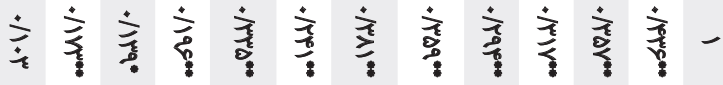

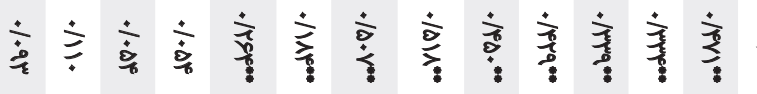

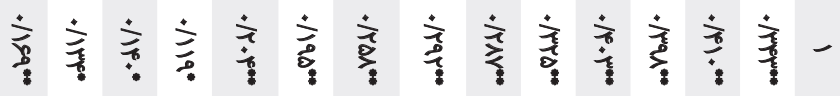

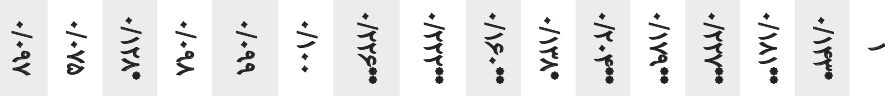

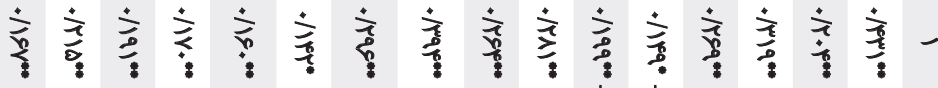

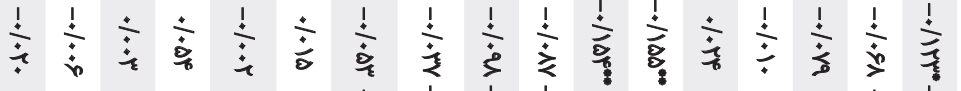

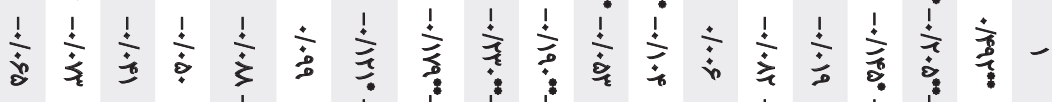

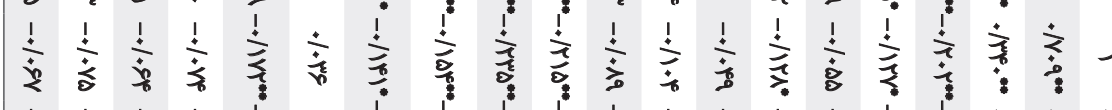

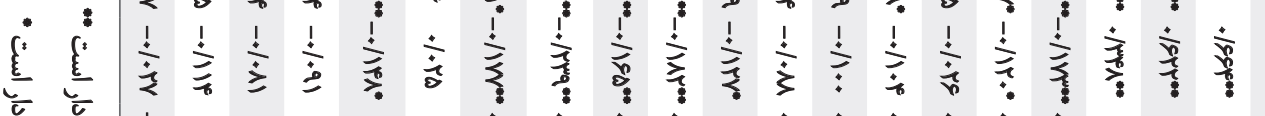

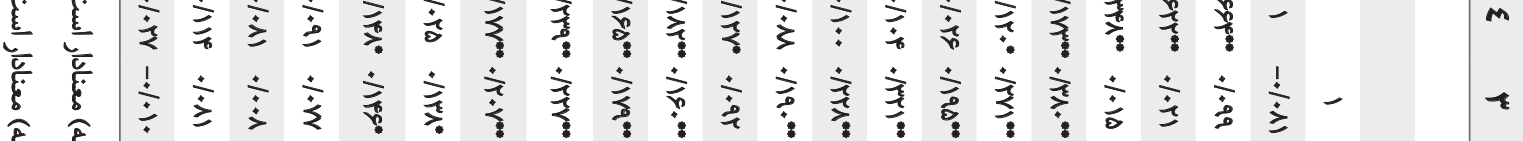

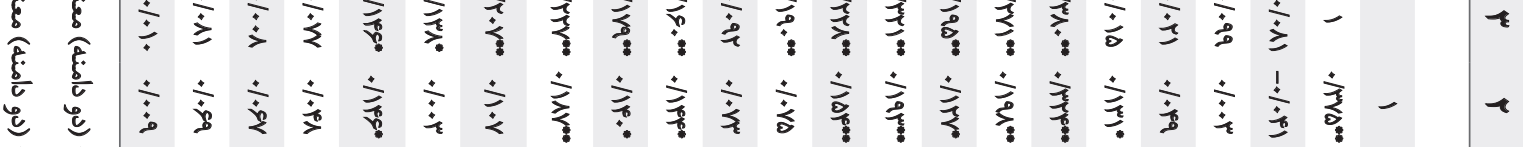

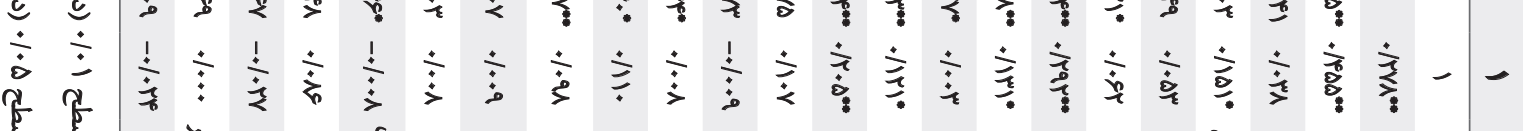

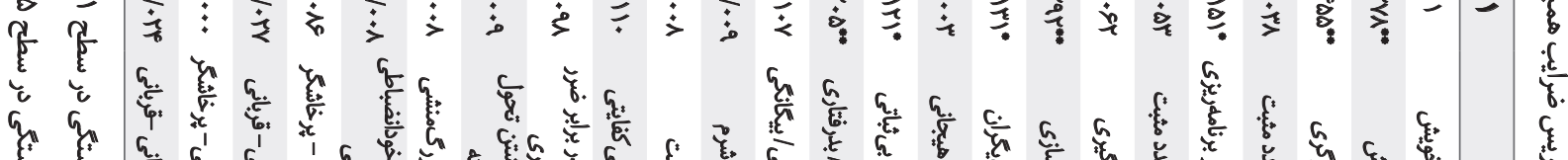

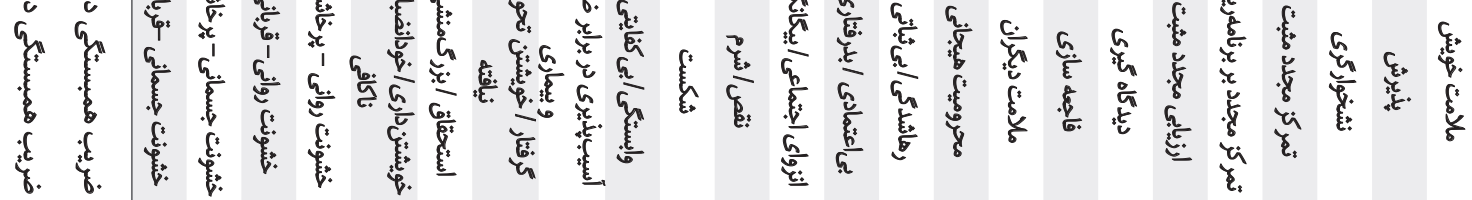




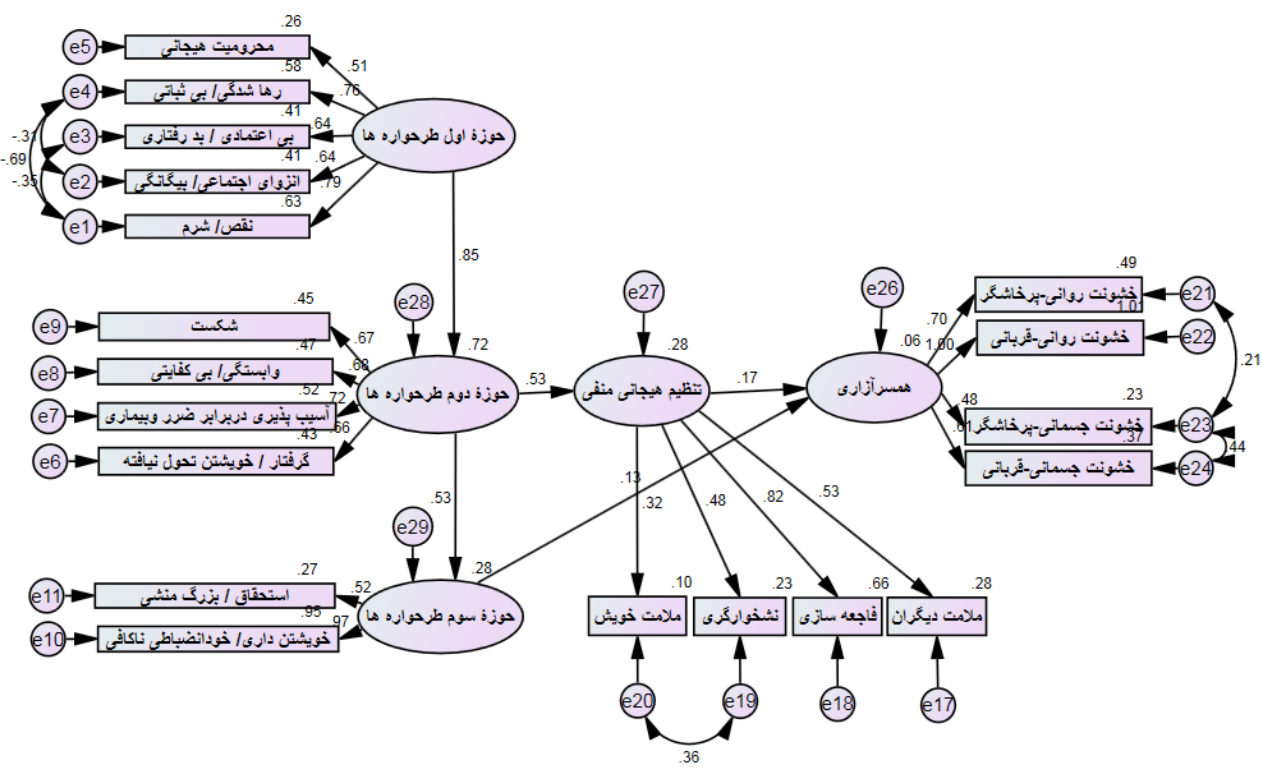

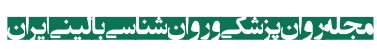

تصوير ا. مدل نقش ميانجى تنظيم هيجان شئاختى در رابطه طرحوارهاى ناساز كار اوليه با همسرآزارى

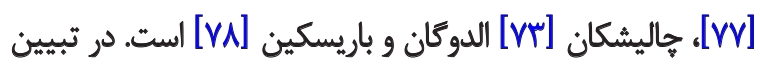

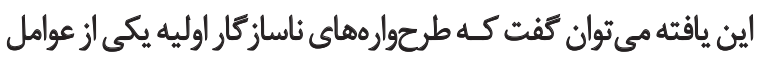

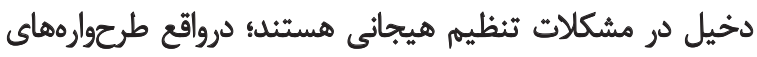

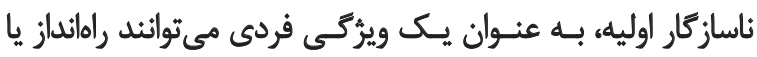

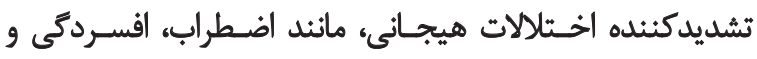

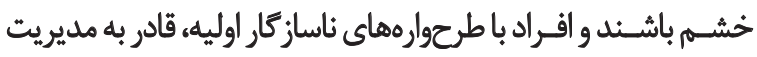

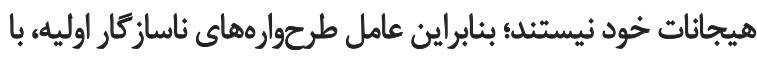

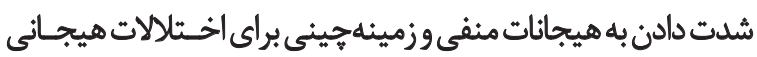

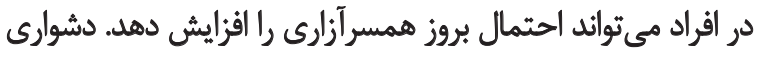

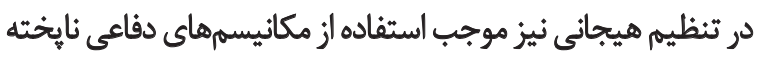

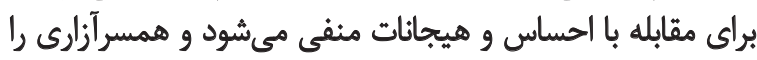

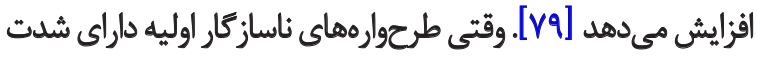

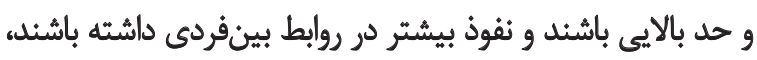

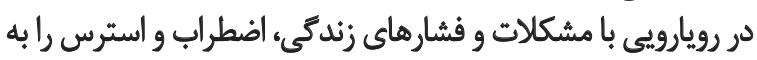

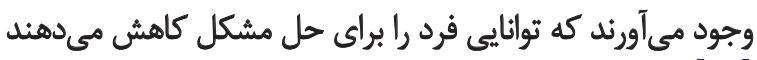

[1 $[$. ]

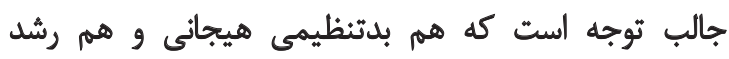

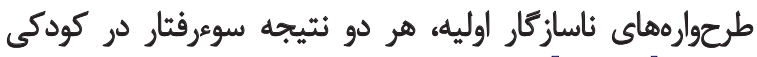

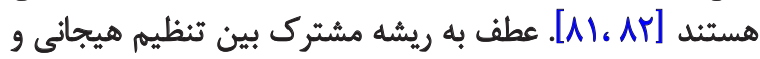

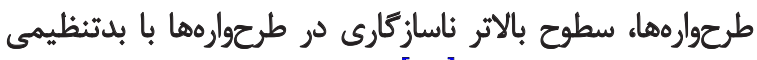

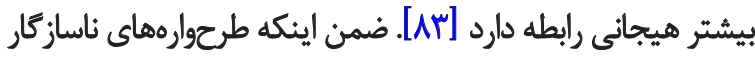

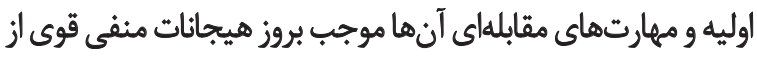

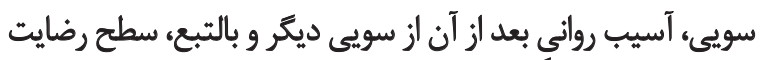

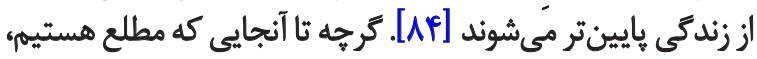

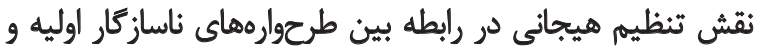

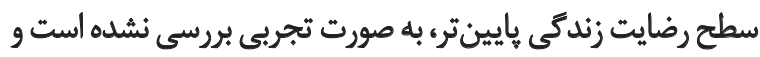

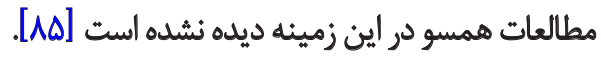

طبق تحقيق جاليشكان [Vr]، افراد با طرحوارهانى حوزه

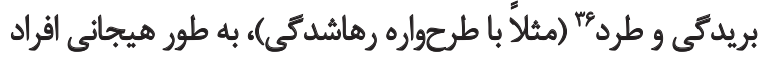

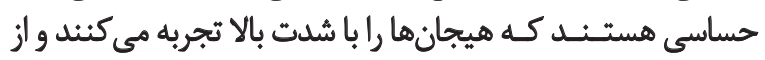

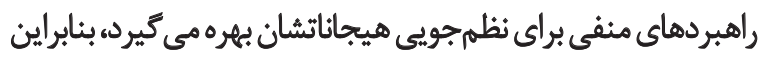

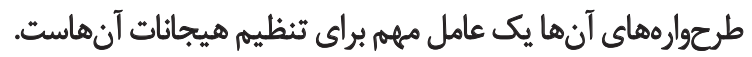

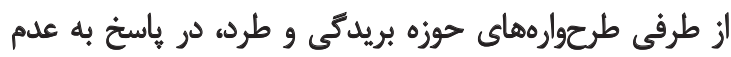

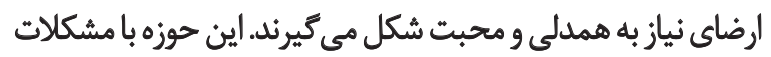

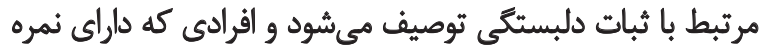

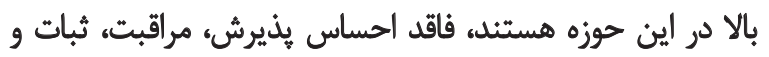

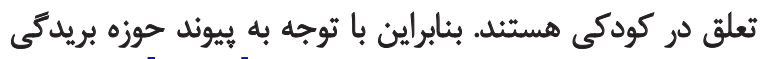

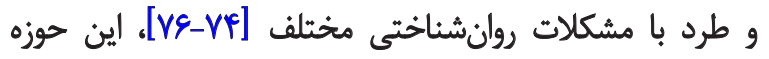

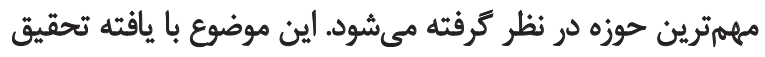

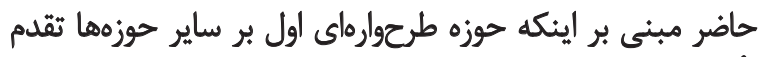

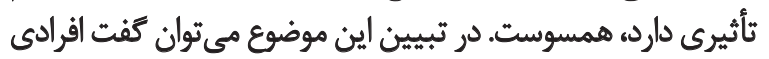

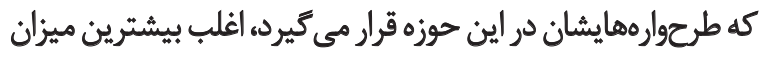

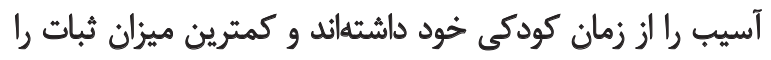

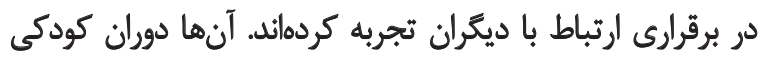

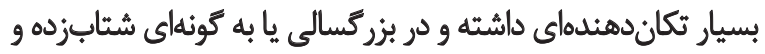

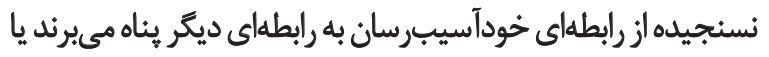

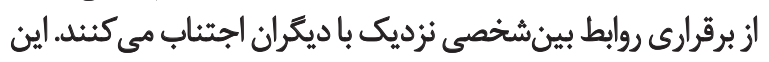

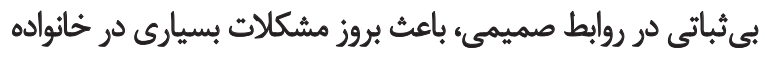
و روابط با همسر مى دشود.

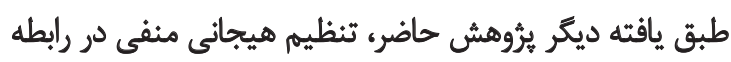

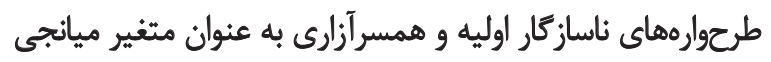

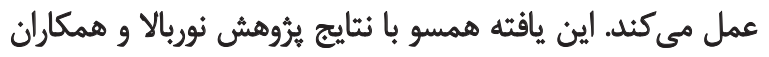

36. Disconnection / Rejection 
جدول F. ضرايب مسير و معنى دارى بارهاي عاملى در مدل اندازهكيرى

\begin{tabular}{|c|c|c|c|c|c|c|c|c|c|}
\hline تتيجه & $\mathbf{R}^{2}$ & معنادارى & الرزش t & خطاي برآلورد & غيراستائدارد & ضرايب استدارد & ختم مي شود به & & رابطه از \\
\hline تأييد & . & & & & $1 / *$ &.$/ 19$ & نقص / شرم & $\leftarrow$ & حوزه اول \\
\hline تأييد &.$/ 14$ & $\%$ & $9 / M^{4}$ &.$/ 79$ & T/AF &.$/ 94$ & انزواى اجتماعى / بيكانكى & $\leftarrow$ & حوزه اول \\
\hline تأييد &.$/ F T$ & .1. & $9 / \pi$. & $\cdot|\Delta|$ & $r / M$ &.$/ 9 F$ & بى اعتمادى / بدرفتارى & $\leftarrow$ & حوزه اول \\
\hline تأييد & .109 & .1. & Q/Ar & .189 & g/A. & $\cdot M$ & رهاشدكى البىثباتي & $\leftarrow$ & حوزه اول \\
\hline ثأييد &.$/ R$ & .10. & $N$ r. &.$/ \Delta$ & $r / M$ &.$/ 01$ & هرووميث هيجائى & $\leftarrow$ & حوزه اول \\
\hline تأييد &.$/ T$ & & & & $1 / \cdots$ & .188 & كرفتًار / خويشتن تحول ثيافته & $\leftarrow$ & حوزه دوم \\
\hline تأييد & - $/ \Delta r$ & $\%$ & $1 . / 79$ &.$/ 10$ & $1 / \Delta 4$ & $\cdot M$ & آسيبئيرى در برابر ضرر و بيمارى & $\leftarrow$ & حوزه دوم \\
\hline تأييد & $\cdot / r V$ & $\%$ & q/Ar &.$/+r$ & $\cdot / \pi T$ &.$/ 81$ & وابستكى / بى كفايتى & $\leftarrow$ & 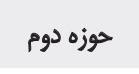 \\
\hline ثأييد &.$/ 10$ & 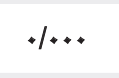 & $9 / 1$ &.$M$ & $1 /$ & $.18 \mathrm{~V}$ & شكست & $\leftarrow$ & حوزه دوم \\
\hline ثأييد &.$/ 90$ & & & & $1 / *$ & +197 & خويشتندارى / خودانضباطى ناكافى & $\leftarrow$ & 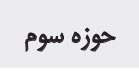 \\
\hline تأييد & $\cdot / r V$ &.$\%$ & $\Delta / / V$ &.$/ r$ & .18. & $+/ A T$ & استحقاق / بزركمنشى & $\leftarrow$ & حوزه سوم \\
\hline 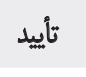 & $+/ 1<9$ & & & & $1 / *$ & $* N$ & خشونت روانى - يرخانشكر & $\leftarrow$ & همسرأزارى \\
\hline تأييد & $1 / 01$ & .10. & $1 . / 4 A$ &.$/ 8$ & V/RY & $11 \%$ & خشونت رواني ـ قريانيى & $\leftarrow$ & همسرآزالى \\
\hline تأييد &.$/ M$ & $\%$ & Q/म & $.1 \cdot 1$ & .181 &.$/ 1 A$ & خشونت جسمانى - يرخاشكر & $\leftarrow$ & همسرآزارى \\
\hline تأييد &.$M Y$ & .1. & $1 . / M r$ &.$/ 11$ & V/P & .181 & خشونت جسمانى ـ قربانى & $\leftarrow$ & همسرآزارى \\
\hline تأييد & .11 & $.10+$ & T/RT &.$/ r$ & $+|\Delta|$ & */Mr & ملامت خويش & $\leftarrow$ & تنظيم هيجانىى \\
\hline تأييد & .188 & .1. & s/Pr &.$/ r V$ & $M^{e}$ & - /AY & فاججانع & $\leftarrow$ & تنظيم هيجانى \\
\hline \multirow[t]{2}{*}{ تأييد } &.$/ M$ & $.1 \ldots$ & $\Delta / \wedge \Delta$ &.$/ 19$ & $1 /$ & . /Ra & نشخولرئرى & $\leftarrow$ & تنظيم هيجانى \\
\hline & $\cdot / M A$ & & & & $1 / \ldots$ & - /ar & ملامت ديكران & $\leftarrow$ & تنظيمه هيجاني \\
\hline
\end{tabular}

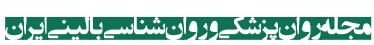

طبق يافته ديكر هيثوهش رابطه مستقيمى بين حوزه سوم طرحوارهاى يعنى محدوديتهاى مختل لآبا همسرآزارى وجود دارد.

37. Impaired limits

جدول ه. ضرايب مسير مستقيمه و معنى دارى اثر سازههاي تحقيق بر يكديكر

\begin{tabular}{|c|c|c|c|c|c|c|c|c|c|}
\hline نتيجه & $\mathbf{R}^{2}$ & معنادارى & t ارشش t & خطائ برأورد & غريراستاندارد & ضرايب استاندارد & ختم مي شود به & & رابطه ازٔ \\
\hline تأييد & $\cdot M r$ & .10. & ข/. &.$/ M I$ & Y/AD &.$/ 1 \Delta \Delta$ & حوزه دوم & $\leftarrow$ & حوزه اول \\
\hline تأييد & $\cdot / M A$ & $+\ldots$ & $\Delta / / \Lambda$ & .1 .9 &.$/ 48$ & $\cdot / \Delta \mu^{\prime}$ & تنظيم هيجانى منفى & $\leftarrow$ & حوزه دوم \\
\hline تأييد & - MA & $+\ldots$ & V/VE &.$/ 1 F$ & $1 / 11$ & $\cdot / \Delta r$ & حوزه سوم & $\leftarrow$ & حوزه دوم \\
\hline تأييد & .1 .8 & $.1 . r$ & $r / Y q$ & .1 .4 &.$/ \cdot v$ &.$/ I V$ & همسرآزازى & $\leftarrow$ & تنظيمه هيجانى منفى \\
\hline تأييد & .1 .8 & .1 .0 & $1 / 98$ & .1 .1 & $.1+r$ &.$/ N$ & همسرآزارى & $\leftarrow$ & حوزه سوم \\
\hline
\end{tabular}


جدول و. ضرايب مسير غيرمستميهم و اثرات كلي در مدل نهايي ثرؤهش

\begin{tabular}{|c|c|c|c|c|c|c|c|c|c|}
\hline \multirow[b]{2}{*}{ نتيجه } & \multirow[b]{2}{*}{ معنادارى } & \multirow[b]{2}{*}{ ارزش t } & \multicolumn{2}{|c|}{ اثرات كلى } & \multicolumn{2}{|c|}{ ضرايب غيرمستقيم } & \multirow[b]{2}{*}{ ختم هي شود به } & & \multirow[b]{2}{*}{ رابطه از } \\
\hline & & & ضرايب & غيراستائبارد & ضرايب & غيراستائدارد & & & \\
\hline تأييد & $\mathrm{P} \leq \star / * \Delta$ & $1 / Q 8>$ & - IAS & $r / \wedge \Delta$ & $\%$ & $+\%$ & حوزه دوم & $\leftarrow$ & حوزه اول \\
\hline تأييد & $P \leq * / \bullet \Delta$ & $1 / 48>$ &.$/ 4 a$ & $1 / M T$ &.$/ 10$ & I/TY & تنظيم هيجانى منفى & $\leftarrow$ & حوزه اول \\
\hline ثأييد & $\mathrm{P} \leq * / * \Delta$ & $1 / 98>$ &.$/ 4 a$ & $m / / Q$ &.$/ 1 \%$ & $r / 18$ & حوزه سوم & $\leftarrow$ & حوزه اول \\
\hline تأييد & $P \leq * / * \Delta$ & $1 / 48>$ &.$/ \mu$ & +118 &.$/ 1 \%$ & $+/ 18$ & همسرأزارى & $\leftarrow$ & حوزه اول \\
\hline تأييد & $\mathrm{P} \leq * / \bullet$ & $1 / Q 8>$ & $.1 \cdot 1$ & $+/ M$ & $1+1$ & $+/ M$ & خشونت جسمانى - قربانى & $\leftarrow$ & حوزه اول \\
\hline تأييد & $P \leq * / \infty$ & I/QS &.$/ \cdot V$ & $+/ 11$ & $\circ \cdot v$ & $+/ 11$ & خشونت جسمانى - يرخاشكر & $\leftarrow$ & حوزه اول \\
\hline تأييد & $\mathrm{P} \leq \star / \bullet \Delta$ & $1 / 98$ &.$/ 1 r$ & $\cdot \pi \varepsilon$ &.$/ 1 r$ &.$/ K 8$ & خشتونت روانى ـ قربانى & $\leftarrow$ & حوزه اول \\
\hline تاييد & $\mathrm{P} \leq . / \bullet$ & $1 / 99>$ & .1 .9 & .118 & .1 .9 & .118 & خشونت روائى - برخاشكر & $\leftarrow$ & حوزه الول \\
\hline تأييد & $\mathrm{P} \leq 1 . \Delta$ & $1 / 98>$ &.$/ F$ & $.19 V$ &.$/ 18$ & $.10 \mathrm{~V}$ & ملامت خويش & $\leftarrow$ & حوزه الول \\
\hline تأييد & $\mathrm{P} \leq \circ / \bullet$ & $1 / 98>$ &.$/ M I$ & $1 / N P$ & $\cdot M$ & $1 / 49$ & تشخواركرى & $\leftarrow$ & حوزه اول \\
\hline تأييد & $\mathrm{P} \leq * / \bullet$ & $1 / 48>$ &.$/ r g$ & $r / R q$ &.$/ M E$ & $r / R q$ & فاجعه سازى & $\leftarrow$ & حوزه اول \\
\hline تأييد & $\mathrm{P} \leq . / \bullet$ & $1 / Q \varphi>$ & $\cdot / M P$ & $1 / \pi T$ & $\cdot / M$ & I/Tr & مامت ديكران & $\leftarrow$ & حوزه اول \\
\hline تأييد & $\mathrm{P} \leq * / * \Delta$ & $1 / Q 9>$ & - = ( & $1 / 19$ & $\cdot \pi r$ & $1 / 19$ & استحقاق /بزركمنشى & $\leftarrow$ & حوزه اول \\
\hline تأييد & $P \leq .1 \bullet \Delta$ & $1 / 98>$ &.$/ A r$ & $m / 18$ &.$/ p f$ & $m / N$ & خويشتندارى/ خوداتضباطى & $\leftarrow$ & حوزه الول \\
\hline تأييد & $\mathrm{P} \leq+1+\infty$ & $1 / Q 9>$ & $\cdot / \Delta V$ & $r / I F$ &.$/ \Delta V$ & $r / M F$ & شكست & $\leftarrow$ & حوزه اول \\
\hline تأييد & $\mathrm{P} \leq+/ \bullet \Delta$ & $1 / Q 9>$ &.$/ A 1$ &.$/ 9$ & .101 & $+/ 9$ & وابستكى /بى كفايتى & $\leftarrow$ & حوزه اول \\
\hline تأييد & $\mathrm{P} \leq+1+\Delta$ & $1 / 48>$ &.$|8|$ & $f(\Delta)$ &.$|8|$ & $\varphi(\Delta)$ & أسيبينيرى در برابر ضرر و & $\leftarrow$ & حوزه اول \\
\hline تأييد & $\mathrm{P} \leq * / \bullet$ & $1 / 98>$ & $.1 \Delta 8$ & $r / 1 \Delta$ & .108 & T/AS & كرفتتار / خويشتن تحول نياقته & $\leftarrow$ & حوزه اول \\
\hline تأييد & $\mathrm{P} \leq * / \bullet$ & $1 / 48>$ &.$|\Delta|$ & $\varphi / M r$ & 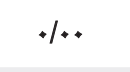 & .1. & محروميت هيجانى & $\leftarrow$ & حوزه اول \\
\hline تأييد & $\mathrm{P} \leq .1+\Delta$ & $1 / 98>$ & $\cdot M$ & $g / 1$. & .1. & 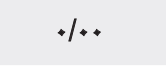 & رهاشدكى/بي ثباتى & $\leftarrow$ & حوزه الول \\
\hline تأييد & $\mathrm{P} \leq * 1 * \Delta$ & $1 / Q 8>$ & .194 & $r / N$ & .1. & $\%$ & بيىاعتمادى / بلرفثنارى & $\leftarrow$ & جوزه اول \\
\hline تأييد & $P \leq+1 * \Delta$ & $1 / 98>$ &.$/ 8 F$ & T/AF & $\%$ & $+1+$ & انزواى اجتماعى/ييكانكى & $\leftarrow$ & حوزه اول \\
\hline تأييد & $\mathrm{P} \leq * / * \Delta$ & $1 / Q 8>$ & $\cdot / \mathrm{Mq}$ & $1 /+$ & $\%$ & $+\%$ & نقص/شرم & $\leftarrow$ & حوزه اول \\
\hline تأييد & $\mathrm{P} \leq * / \bullet$ & $1 / Q>$ & . & $\cdot / 48$ & $\%$ & +1. & تنظيم هيجانى منفى & $\leftarrow$ & حوزه دوم \\
\hline تأييد & $\mathrm{P} \leq * 1 * \mathrm{~A}$ & $1 / 98>$ & $\cdot(\Delta)^{\mu}$ & $1 / 11$ & .1. & .10 & حوز هو مون & $\leftarrow$ & حوزه دور \\
\hline تأييد & $\mathrm{P} \leq . / \bullet$ & $1 / 98>$ &.$/ 18$ & .1 .8 & .118 & .1 .8 & همسرآزارى & $\leftarrow$ & حوزه دوم \\
\hline ثأييد & $P \leq * / \bullet$ & $1 / 98>$ &.$\Lambda$ & .1 .8 & .11 & .1 .8 & خشونت جسمائي ـ قربائي & $\leftarrow$ & حوزه دوم \\
\hline تأييد & $\mathrm{P} \leq \bullet / \bullet \Delta$ & $1 / 98>$ & $.1 \cdot 1$ & $.1 . p$ & $\cdot 1+1$ & $\circ+\varphi$ & خشوثت جسمائى - يرخاشكر & $\leftarrow$ & حوزه دوم \\
\hline تأييد & $\mathrm{P} \leq * 1 * 0$ & $1 / Q 8>$ &.$/ 18$ & .1 .9 & .118 & .1 .9 & حُشوثتث روانتى - قربانى & $\leftarrow$ & حوزه دوم \\
\hline تأييد & $\mathrm{P} \leq+1 * \Delta$ & $1 / 98>$ &.$/ 11$ & .1 .8 &.$/ 11$ & .1 .8 & خشونت روانى - يرخاشكر & $\leftarrow$ & حوزه دوم \\
\hline
\end{tabular}




\begin{tabular}{|c|c|c|c|c|c|c|c|c|c|}
\hline \multirow[b]{2}{*}{ تتيجه } & \multirow[b]{2}{*}{ معنادارى } & \multirow[b]{2}{*}{ ارزش t t } & \multicolumn{2}{|c|}{ اثرات كلى } & \multicolumn{2}{|c|}{ ضرايب غيرمستقيم } & \multirow[b]{2}{*}{ ختم مىشود به } & & \multirow[b]{2}{*}{ رابطه از } \\
\hline & & & ضراليب & غيراستاندارد & ضرايب & غيراستاندارد & & & \\
\hline تأييد & $P \leq \bullet / \bullet \varnothing$ & $1 / 98>$ &.$/ I V$ & $\cdot / M F$ & $+/ 1 Y$ & $\cdot / H F$ & ملامت خويش & $\leftarrow$ & حوزه دوم \\
\hline تأييد & $\mathrm{P} \leq \bullet / \bullet$ & las> &.$/ T \Delta$ &.$|\Delta|$ & . RA &.$|1|$ & تشخْواركرى & $\leftarrow$ & حوزه دوم \\
\hline تأييد & $P \leq \bullet / \bullet$ & lass & . & $+/ \Lambda$ & t/Mr & $+/ \Lambda$ & فاجعduliزى & $\leftarrow$ & حوزه دوم \\
\hline تأييد & $\mathrm{P} \leq \bullet / \bullet$ & l/qs> &.$/ M A$ & $+/ 48$ & $+/ r A$ & $* / 48$ & ملامت ديكران & $\leftarrow$ & حوزه دوم \\
\hline تأييد & $\mathrm{P} \leq . / . \Delta$ & $1 / 48>$ &.$/ M A$ & .188 &.$/ T A$ & .188 & استحقاق / بزركمنشى & $\leftarrow$ & حوزه دوم \\
\hline تأييد & $P \leq \bullet / \bullet \Delta$ & l/qe> & - /ar & $M$ & + /ar & $1 / 1$ & خويشتندارى/خودانضباطى & $\leftarrow$ & حوزه دوم \\
\hline تأييد & $\mathrm{P} \leq \bullet / \bullet$ & $1 / q e>$ & . IeV & $M$ & .1. & $\%$ & شكست & $\leftarrow$ & حوزه دوم \\
\hline تأييد & $\mathrm{P} \leq . / \bullet$ & $1 / q \varphi>$ &.$/ 8 \lambda$ & $\cdot / M T$ & +1. & $\%$ & وابستكى /بى كفايتى & $\leftarrow$ & حوزه دوم \\
\hline تأييد & $\mathrm{P} \leq . / \odot \Delta$ & laes & $\cdot M$ & $1 / \Delta 1$ & .1. & .1. & أسيبذيذيرى در برابر ضرر و & $\leftarrow$ & حوزه دوم \\
\hline تأييد & $P \leq \star / \bullet$ & $\mid / Q s>$ & .189 & $1 / *$ & + & $\%$ & كرفتار / خويشتن تحولنياقته & $\leftarrow$ & حوزه دوم \\
\hline تأييد & $\mathrm{P} \leq . / \bullet \Delta$ & 1/aes &.$/ H$ & .1 .4 & .10 & $\%$ & همسرآزازى & $\leftarrow$ & حوزه سوم \\
\hline تأييد & $\mathrm{P} \leq \bullet / \bullet$ & l/as & $.1 \cdot 1$ &.$/ 4 r$ & $.1 \cdot \Lambda$ & $.1 . r$ & خشونت جسمائى ـقربائى & $\leftarrow$ & حوزه سوم \\
\hline تأييد & $\mathrm{P} \leq .1+\Delta$ & $\mid / q \varphi>$ & .1 .8 & H.r & .1 .8 & .104 & خُشونت جسمانى - برخاشكر & $\leftarrow$ & حوزه سوم \\
\hline تأييد & $P \leq+1+\Delta$ & laes & זו/. & $+1+4$ &.$/ 1 \pi$ & .1 .4 & خشوئت روائى ـ قربانى & $\leftarrow$ & حوزه سوم \\
\hline تأييد & $\mathrm{P} \leq+/ \bullet \otimes$ & l/as> & .1 .9 & $h$ & $+1+9$ & $4+r$ & خشونت روانى - يرخاشكر & $\leftarrow$ & حوزه سوم \\
\hline تأييد & $\mathrm{P} \leq \bullet / \bullet$ & $1 / q \&>$ &.$/ \mathrm{V}$ & $.1 \cdot v$ & .1. & $\%$ & همسرآزارى & $\leftarrow$ & تنظيم هيجائي \\
\hline تأييد & $\mathrm{P} \leq * / \cdot \Delta$ & l/as> &.$/$ & $+1+1$ & .11 & $.1 \cdot 1$ & خشونت جسمانى ـ قربانى & $\leftarrow$ & تنظيم هيجانى \\
\hline تأييد & $\mathrm{P} \leq . / \bullet \Delta$ & l/Qs &.$/ \bullet \wedge$ & $.1 \% \Delta$ & $+1+1$ & 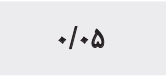 & خشونت جسمانى - يرخاشكر & $\leftarrow$ & تنظيم هيجانى \\
\hline تأييد & $\mathrm{P} \leq . / \Delta$ & 1/ass &.$/ \mathrm{V}$ &.$M$ & $.11 \mathrm{~V}$ &.$M 11$ & خُشويت روائي - قربائيى & $\leftarrow$ & تنظيم هيجانى \\
\hline تأييد & $\mathrm{P} \leq . / \bullet$ & l/as> &.$/ r$ &.$/ . V$ &.$/ 1 r$ & $\% v$ & خشونت رواني - برخاشكر & $\leftarrow$ & تئظيم هيجائئ \\
\hline تأييد & $\mathrm{P} \leq * / \bullet$ & l/as> & $\cdot / M r$ & $\cdot|\Delta|$ & $.1 *$ & $\%$ & مالامت خويش & $\leftarrow$ & تنظيم هيجائي \\
\hline ت تأييد & $P \leq * / \bullet$ & l/qe> &.$/ \& A$ & $1 /$ & $+1+$ & .10 & تشخواركرى & $\leftarrow$ & تنظيم هيجانى \\
\hline تأييد & $P \leq * / * \theta$ & V/as> & - /Ar & $M F$ & $+1+$ & $\%$ & فاجعهuli & $\leftarrow$ & تنظيم هيجانى \\
\hline تأييد & $\mathrm{P} \leq \bullet / \bullet \diamond$ & l/as> & . /ar & $1 *$ & $\%$ & 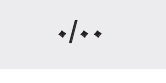 & ملامت ديكران & $\leftarrow$ & تنظيم هيجانى \\
\hline تأييد & $\mathrm{P} \leq . / \odot$ & l/qes &.$/ 81$ & V/IF & $+1 *$ & $\%$ & خُشونت جسمانى ـ قربانى & $\leftarrow$ & همسرآزالىى \\
\hline تأييد & $P \leq . / \bullet$ & |/Qs> &.$/ 4 \lambda$ & .181 & $+1+$ & $\%$ & خشونت جسمانى - يرخاشكر & $\leftarrow$ & همسرآزارى \\
\hline تأييد & $\mathrm{P} \leq . / \diamond$ & $1 / 49>$ & $1 / *$ & V/gr & $+*$ & .1. & خشونت روانى ـ قربائى & $\leftarrow$ & همسروآزارى \\
\hline تأييد & $\mathrm{P} \leq \bullet / \bullet$ & las> & $\cdot N$ & $V *$ & +1. & $\%$ & خشونت روائى - يرخاشكر & $\leftarrow$ & همسر آزارى \\
\hline
\end{tabular}


جدول V• برازش مدل

\begin{tabular}{|c|c|c|c|c|c|c|c|}
\hline RFI & CFI & NFI & AGFI & GFI & RMSEA & (كايى بر درجه آزادى) X²/dF & نام شاحُص برازش \\
\hline $.19<$ & $. / 9<$ & $. / 9<$ & $\cdot / A \Delta<$ & $. / 9<$ & $\cdot|\cdot \lambda\rangle$ & $r>$ & 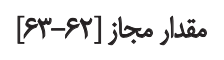 \\
\hline.$/ 9$ & . $9 \Delta \mathrm{r}$ & $+/ 9$ & $. / 9+$. & ./ATA & $+1+F \Delta$ & $1 / \Delta 9 \Delta$ & مقدار بهدستآمده \\
\hline
\end{tabular}

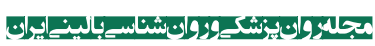

ساكن شهر تهران بود كه دامنه واريانس را محدود مي كرد. ضمن

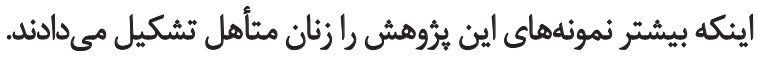

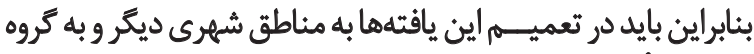
مردان مثتأهل احتياط كرد.

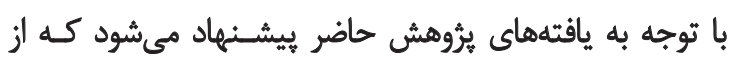

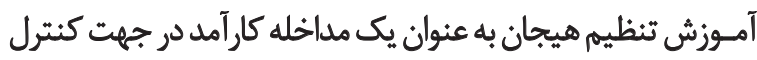

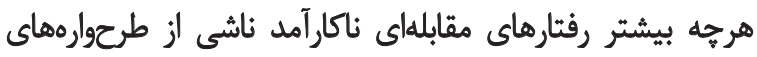

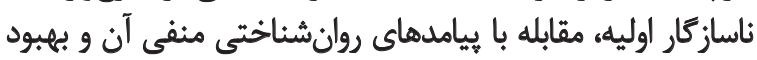

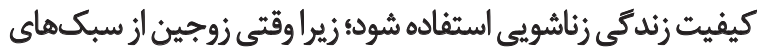

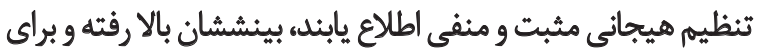

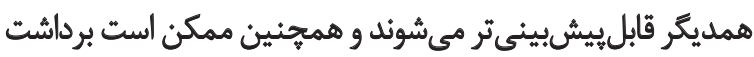

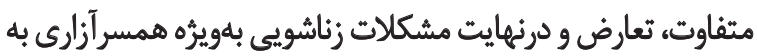

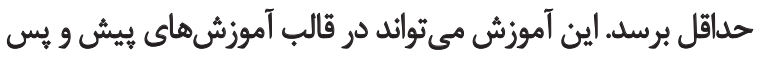

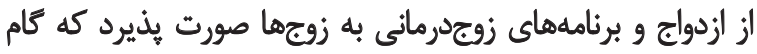

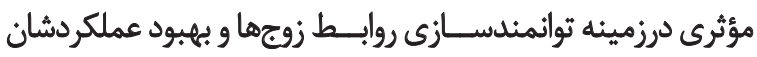

خواهد بود.

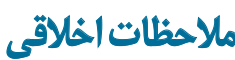 \\ ي بيروى أز اصول اخلاق يثوهش}

با توجه به اينكه رعايت اصول اخلاقي و حرمت انساني يهيشنياز هر

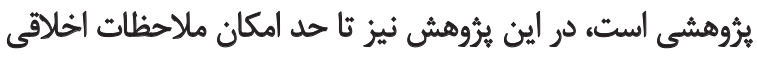

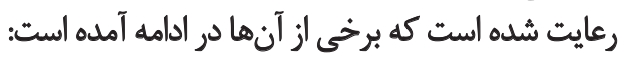

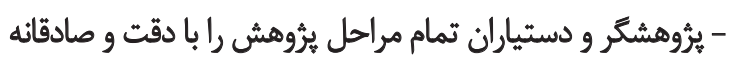

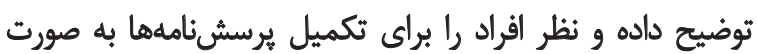
داوطلبانه جلب كردهاند.

- كليه برسش نامهها فاقد نام و نام خانوادكى بوده و شركت كنئنان

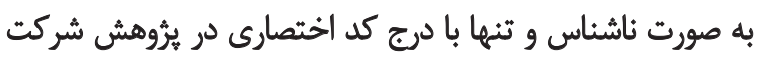
كردماند.

- در بالاو ابتداي يرسش نامهها به صورت كتبى درج شده است كه

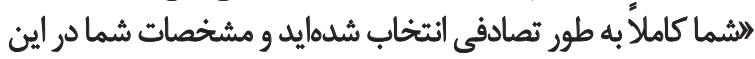

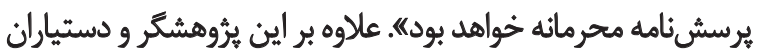

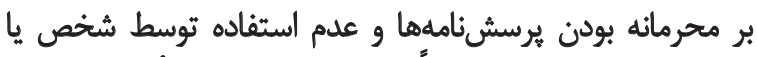

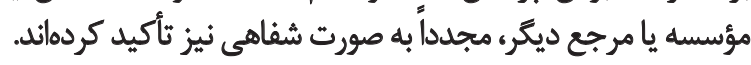

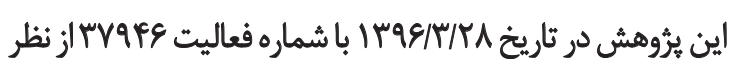

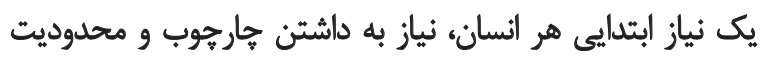

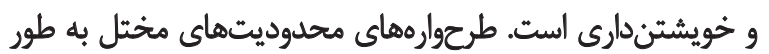

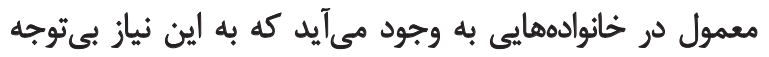

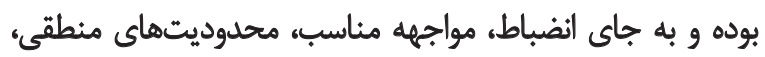

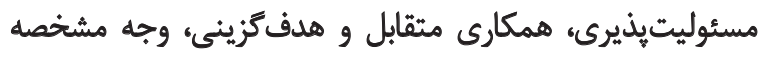

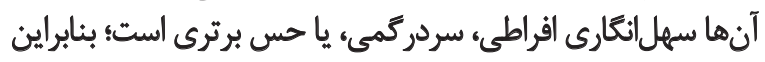

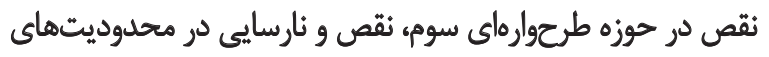

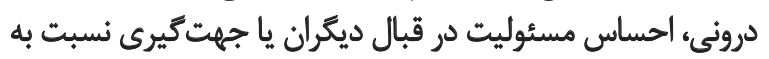

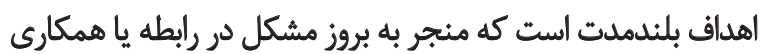

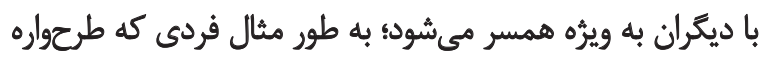

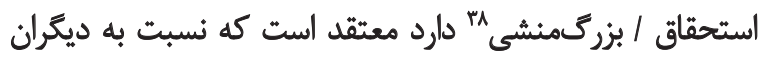

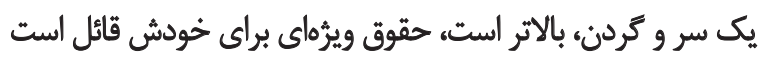

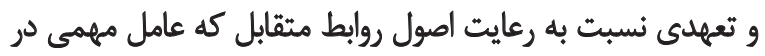

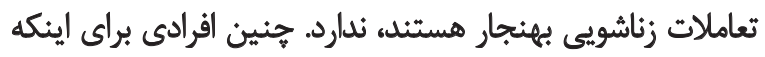

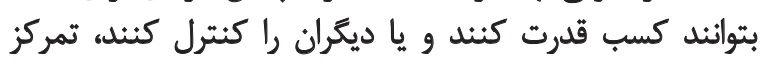

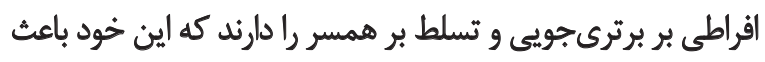

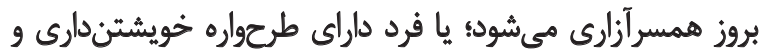

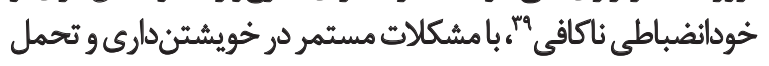

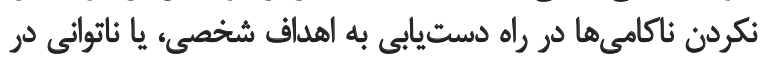

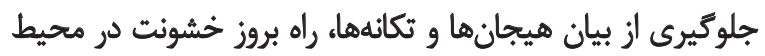

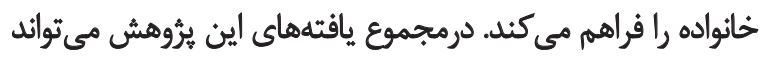

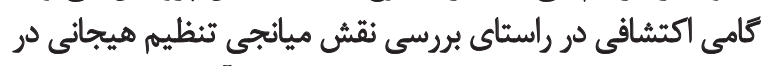

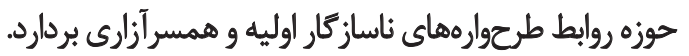

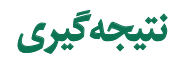
به طور كلى، نتثايج يثروهش حاضر نشان داد وجود تنظيم هيجاني

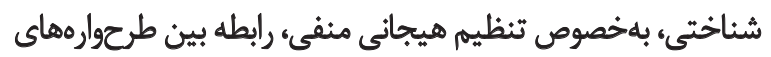

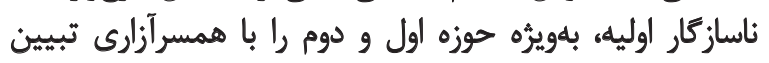

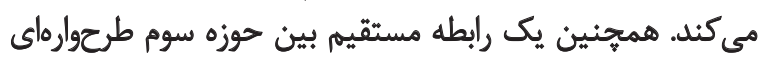

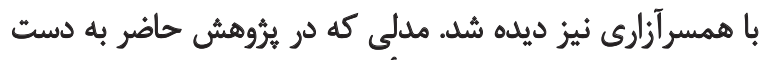

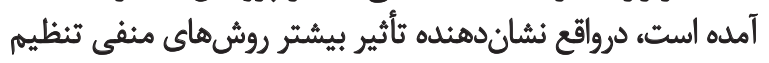

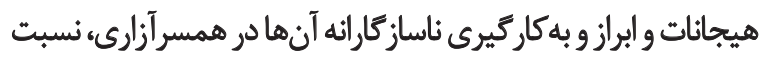

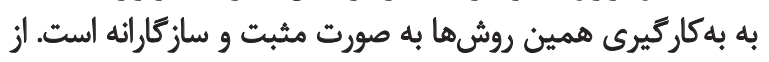

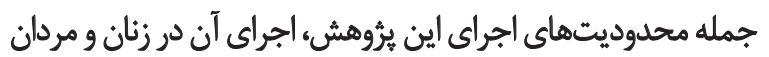

38. Entitlement / Grandiosity

39. Insufficient self-control / Self-discipline 


$$
\begin{aligned}
& \text { رعايت اصول اخلاق در يُروهش، مورد تأييد قرار كرفته است و منع } \\
& \text { اخلاقى براى انتشار ندارد. } \\
& \text { هامى مالى } \\
& \text { مشاركت نويسيندكان }
\end{aligned}
$$

تمام نويسندكان در طراحي، اجرا و نكارش همه بخشهاي ئرؤرهش حاضر مشاركت داشتهاند.

$$
\text { تعارض منافع }
$$

بنا بر اظهار نويسنده مسئول، اين مقاله تعارض منافع ندارد. 


\section{References}

[1] Straus MA. Physical assaults by wives: A major social problem. Newburty Park: Current Controversies on Family Violence; 1993. http://www.498a.org/contents/dv/WomenDomesticViolence. pdf

[2] Barnett OW, Miller-Perrin CL, Perrin RD. Family violence across the lifespan. New York: Sage Publications, Inc; 2010.

[3] Mohammadkhani P, Azadmehr H. [Problems of family: Sychopatology and personal-relationship problems of female victims of Family violence (Persian)]. Social Welfare Quarterly. 2008; 27(7):7-28. http://refahj.uswr.ac.ir/article-1-302-en.html

[4] Harne L, Rad FJ. Tackling domestic violence. New York: Open University Press; 2008.

[5] Standley K. Family law. New York: Palgrave Macmillan; 2006.

[6] Yousefabad MZ, Alilou MM. Comparison of attachment styles and personality sides between women who are victim of domestic violence and ordinary women. Procedia-Social And Behavioral Sciences. 2013; 84:1005-9. [DOI:10.1016/j.sbspro.2013.06.689]

[7] Nazparvar B. Wife abuse. Women in Development and Politics. 2002; 1(3):25-44. https://jwdp.ut.ac.ir/article_26915_71cffa93f488 22faa5c9dce9a9808579.pdf

[8] Miles A. When faith is used to justify abuse. The American Journal of Nursing. 2006; 99(5):32-5. [DOI:10.2307/3472268]

[9] Osmond M, Thorne B. Feminist theories: The social construction of gender in families and society. In: Boss PG, Doherty WJ, LaRossa R, Schumm WR, Steinmetz SK, editors. Sourcebook of Family Theories and Methods: A Contextual Approach. Amsterdam: Springer; 1993. https://link.springer.com/chapter/10.1007/978-0-387-85764-0_1

[10] Karney BR, Bradbury TN, Fincham FD, Sullivan KT. The role of negative affectivity in the association between attributions and marital satisfaction. Journal of Personality and Social Psychology. 1994; 66(2):413-24. [DOI:10.1037/0022-3514.66.2.413] [PMID]

[11] Anderson KL. Gender, status, and domestic violence: An integration of feminist and family violence approaches. Journal of Marriage and the Family. 1997; 59(3):655-69. [DOI:10.2307/353952]

[12] Viano EC. Violence among intimates: Major issues and approaches. Washington D.C,: The American University; 1992.

[13] Walker LE. The battered woman syndrome. New York: Springer Publishing Company; 2016. [DOI:10.1891/9780826170996]

[14] Johnston ME. Correlates of early violence experience among men who are abusive toward female mates. In Hotaling GT, Finkelhor D, Kirkpatrick JT, Straus MA, editors. Family Abuse and Its Consequences: New Directions in Research. New York: Sage Publications, Inc; 1988. https://psycnet.apa.org/record/1988-98453-013

[15] Peterson C, Maier SF, Seligman ME. Learned helplessness: A theory for the age of personal control: Oxford: Oxford University Press; 1993.

[16] Straus MA. A sociological perspective on the prevention and treatment of wife beating. Battered women: A Psychosociological Study of Domestic Violence. 1977:194-239.
[17] Gover AR, Kaukinen C, Fox KA. The relationship between violence in the family of origin and dating violence among college students. Journal of Interpersonal Violence. 2008; 23(12):1667-93. [DOI:10.1177/0886260508314330] [PMID]

[18] Dixon L, Graham-Kevan N. Understanding the nature and etiology of intimate partner violence and implications for practice and policy. Clinical Psychology Review. 2011; 31(7):1145-55. [DOI:10.1016/j.cpr.2011.07.001] [PMID]

[19] Young JE. Cognitive therapy for personality disorders: A schema-focused approach. Washington: Professional Resource Press/ Professional Resource Exchange; 1999. https://psycnet.apa.org/ record/1999-02395-000

[20] Jovev M, Jackson HJ. Early maladaptive schemas in personality disordered individuals. Journal of Personality Disorders. 2004 18(5):467-78. [DOI:10.1521/pedi.18.5.467.51325] [PMID]

[21] Shorey RC, Stuart GL, Anderson S. The early maladaptive schemas of an opioid-dependent sample of treatment seeking young adults: A descriptive investigation. Journal of Substance Abuse Treatment. 2012; 42(3):271-8. [DOI:10.1016/j.jsat.2011.08.004] [PMID] [PMCID]

[22] Thimm JC. Personality and early maladaptive schemas: A five-factor model perspective. Journal of Behavior Therapy and Experimental Psychiatry. 2010; 41(4):373-80. [DOI:10.1016/j. jbtep.2010.03.009] [PMID]

[23] Mason O, Platts H, Tyson M. Early maladaptive schemas and adult attachment in a UK clinical population. Psychology and Psychotherapy: Theory, Research and Practice. 2005; 78(4):549-64. [DOI:10.1348/147608305X41371] [PMID]

[24] Yang S, Mulvey EP. Violence risk: Re-defining variables from the first-person perspective. Aggression and Violent Behavior. 2012; 17(3):198-207. [DOI:10.1016/j.avb.2012.02.001] [PMID] [PMCID]

[25] Nordahl HM, Holthe H, Haugum JA. Early maladaptive schemas in patients with or without personality disorders: Does schema modification predict symptomatic relief? Clinical Psychology \& Psychotherapy. 2005; 12(2):142-9. [DOI:10.1002/cpp.430]

[26] Holt SL, Tompsett J. Childhood maltreatment as a predictor of subsequent interpersonal problems in young adult relationships: The mediating role of maladaptive schemas. Journal of Clinical Psychology. 2013; 53:319-29. https://etd.ohiolink.edu/ apexprod/rws_olink/r/1501/10?clear=10\&p10_accession_ num=bgsu1383309250

[27] Barrett LF, Gross J, Christensen TC, Benvenuto M. Knowing what you're feeling and knowing what to do about it: Mapping the relation between emotion differentiation and emotion regulation. Cognition \& Emotion. 2001; 15(6):713-24. [DOI:10.1080/02699930143000239]

[28] Gross JJ. Antecedent-and response-focused emotion regulation divergent consequences for experience, expression, and physiology. Journal of Personality and Social Psychology. 1998; 74(1):224. [DOI:10.1037/0022-3514.74.1.224] [PMID]

[29] Gross JJ. Emotion regulation in adulthood: Timing is everything. Current Directions in Psychological Science. 2001; 10(6):214-9. [DOI:10.1111/1467-8721.00152]

[30] Eisenberg N, Fabes RA, Guthrie IK, Reiser M. Dispositional emotionality and regulation: their role in predicting quality of social functioning. Journal of Personality and Social Psychology. 2000; 78(1):136-57. [DOI:10.1037/0022-3514.78.1.136] [PMID] 
[31] Gross JJ. The emerging field of emotion regulation: an integrative review. Review of General Psychology. 1998; 2(3):271-99. [DOI:10.1037/1089-2680.2.3.271]

[32] Campbell-Sills L, Barlow DH. Incorporating emotion regulation into conceptualizations and treatments of anxiety and mood disorders. In: Gross JJ, editor. Handbook of emotion regulation. New York: The Guilford Press; 2007. https://psycnet.apa.org/ record/2007-01392-027

[33] Gross JJ, Levenson RW. Hiding feelings: the acute effects of inhibiting negative and positive emotion. Journal of Abnormal Psychology. 1997; 106(1):95. [DOI:10.1037/0021-843X.106.1.95]

[34] Garnefski N, Kraaij V. Relationships between cognitive emotion regulation strategies and depressive symptoms: A comparative study of five specific samples. Personality and Individual differences. 2006; 40(8):1659-69. [DOI:10.1016/j.paid.2005.12.009]

[35] Garnefski N, Kraaij V, Spinhoven P. Negative life events, cognitive emotion regulation and emotional problems. Personality and Individual Differences. 2001; 30(8):1311-27. [DOI:10.1016/S01918869(00)00113-6]

[36] Mansell W, Harvey A, Watkins ER, Shafran R. Cognitive behavioral processes across psychological disorders: A review of the utility and validity of the transdiagnostic approach. International Journal of Cognitive Therapy. 2008; 1(3):181-91. [DOI:10.1521/ ijct.2008.1.3.181]

[37] Gratz KL, Roemer L. Multidimensional assessment of emotion regulation and dysregulation: Development, factor structure, and initial validation of the difficulties in emotion regulation scale. Journal of Psychopathology and Behavioral Assessment. 2004; 26(1):41-54. [DOI:10.1023/B:JOBA.0000007455.08539.94]

[38] Gottman JM. What predicts divorce?: The relationship between marital processes and marital outcomes. New York: Psychology Press; 2014. [DOI:10.4324/9781315806808] [PMID] [PMCID]

[39] Bradbury TN, Fincham FD. Attributions in marriage: Review and critique. Psychological Bulletin. 1990; 107(1):3-33. [DOI:10.1037/0033-2909.107.1.3] [PMID]

[40] Diamond LM, Aspinwall LG. Emotion regulation across the life span: An integrative perspective emphasizing self-regulation, positive affect, and dyadic processes. Motivation and Emotion. 2003; 27(2):125-56. [DOI:10.1023/A:1024521920068]

[41] Kappas A. Emotion and regulation are one! Emotion Review. 2011;3(1):17-25. [DOI:10.1177/1754073910380971]

[42] Coan JA. Toward a neuroscience of attachment. Handbook of attachment: Theory, research, and clinical applications. New York: The Guilford Press; 2008. https://psycnet.apa.org/record/2008-13837-011

[43] Nahidi F, Kariman Na-s, Valaee N, Fazli Z. Postmenopausal age and its related factors in postmenopausal women in Tehran. Research in Medicine. 2010; 33(4):258-65. http:/ / pejouhesh.sbmu. ac.ir/article-1-694-fa.html

[44] Rabiee M, Akbari H, Davati A, Moghadamnia M. Investigating the influence of mood-changes and effective elements of peri menopause on patient's companions referred to hospitals related to Shahed University in 2010- 2009. Iranina Journal of Obstetrics Gynecology and Infertility. 2012; 15(15):8-15. http:/ /ijogi.mums. ac.ir/article_5680.html

[45] Stevens JP. Applied multivariate statistics for the social sciences. London: Routledge; 2012. [DOI:10.4324/9780203843130]
[46] Wang CEA, Halvorsen M, Eisemann M, Waterloo K. Stability of dysfunctional attitudes and early maladaptive schemas: A 9-year follow-up study of clinically depressed subjects. Journal of Behavior Therapy and Experimental Psychiatry. 2010; 41(4):396-89. [DOI:10.1016/j.jbtep.2010.04.002] [PMID]

[47] Young JE, Brown G. Cognitive therapy for personality disorders: A schema-focused approach. New York and London: The Guildford Press; 1994. https://books.google.com/books?id=Q C82CwAAQBAJ\&pg=PA480\&dq

[48] Welburn K, Coristine M, Dagg P, Pontefract A, Jordan S. The Schema Questionnaire-Short Form: Factor analysis and relationship between schemas and symptoms. Cognitive Therapy and Research. 2002; 26(4):519-30. [DOI:10.1023/A:1016231902020]

[49] Ahi G. [Standardization of short - form of young schema Inventory SQ-SF (factor structure) between Tehran university students (Persian)] [PhD. dissertation]. Tehran: Allame Tabatabaie University. 2005.

[50] Sadooghi Z, Aguilar-Vafaie ME, Rasoulzadeh Tabatabaie K, Esfehanian N. [Factor analysis of the young schema questionnaireshort form in a nonclinical Iranian sample (Persian)]. Iranian Journal of Psychiatry and Clinical Psychology. 2008; 14(2):214-9. http://ijpcp.iums.ac.ir/article-1-474-en.html

[51] Aminabadi Z, Dehghani M, Khodapanahi MK. [Factor structure and validation of the Cognitive Emotion Regulation Questionnaire (Persian)]. International Journal of Behavioral Sciences. 2011; 5(4):365-71. https://iranjournals.nlai.ir/handle/123456789/218555

[52] Besharat MA. Study of psychometric properties of Cognitive Emotion Regulation Questionnaire [Research Report]. Tehran: University of Tehran; 2009. http://journals.sbmu.ac.ir/en-jnm/ article/viewFile/7360/8114

[53] Hasani J. [The psychometric properties of the Cognitive Emotion Regulation Questionnaire (CERQ) (Persian)]. Journal of Clinical Psychology. 2010; 2(3 and 7):73-83. https:/ /jcp.semnan.ac.ir/ article_2031_7143fb6b44350b1f947dd2634d166d96.pdf

[54] Besharat MA, Bazazian S. Psychometric properties of Cognitive Emotion Regulation Questionnaire in a sample of community with regulated emotional understanding. Nursing and Midwifery. 2011; 24(84):61-70. https://www.sid.ir/Fa/Journal/ ViewPaper.aspx?ID=258750

[55] Samani S, Sadeghi L. Sufficiency of psychometric properties of the Cognitive Emotion Regulation Questionnair (CERQ). Journal of Pscychological Models and Methods. 2010; 1(1):51-62. https:// www.sid.ir/fa/journal/ViewPaper.aspx?id=188922

[56] Straus MA. Measuring intrafamily conflict and aggression: The Conflicts Tactic Scale (CTS). Journal of Marriage and Family. 1979; 41(1):75-88. [DOI:10.2307/351733]

[57] Straus MA, Hamby SL, Boney-McCoy S, Sugarman DB. The revised Conflict Tactics Scales (CTS2) development and preliminary psychometric data. Journal of Family Issues. 1996; 17(3):283316. [DOI:10.1177/019251396017003001]

[58] Moraes CL, Reichenheim ME. Cross-cultural measuremen equivalence of the Revised Conflict Tactics Scales (CTS2) Portuguese version used to identify violence within couples. Cadernos de Saúde Pública. 2002; 18:783-96. [DOI:10.1590/S0102311X2002000300022] [PMID]

[59] Newton RR, Connelly CD, Landsverk JA. An examination of measurement characteristics and factorial validity of the Revised 
Conflict Tactics Scale. Educational and Psychological Measurement. 2001; 61(2):317-35. [DOI:10.1177/00131640121971130]

[60] Straus MA, Ramirez IL. Gender symmetry in prevalence, severity, and chronicity of physical aggression against dating partners by university students in Mexico and USA. Aggressive Behavior: Official Journal of the International Society for Research on $\mathrm{Ag}$ gression. 2007; 33(4):281-90. [DOI:10.1002/ab.20199] [PMID]

[61] Panaghi L, Dehghani M, Abbasi M, Mohammadi S, Maleki G. Investigating reliability, validity and factor structure of the revised conflict tactics scale. Journal of Family Research. 2011; 7(1):103-7. https://www.sid.ir/fa/journal/ViewPaper.aspx?id=129794

[62] Dion PA. Interpreting structural equation modeling results: A reply to Martin and Cullen. Journal of Business Ethics. 2008, 83(3): 365-8. [DOI:10.1007/s10551-007-9634-7]

[63] Hooman HA. Structural equation modeling with LISREL application. Tehran: Samt; 2010.

[64] Bradbury TN, Fincham FD, Beach SR. Research on the nature and determinants of marital satisfaction: A decade in review. Journal of Marriage and Family. 2000; 62(4):964-80. [DOI:10.1111/ j.1741-3737.2000.00964.x]

[65] Falah Chay SR, Zarei E, Normandy Pour F. Investigating the relationship between maladaptive schemas and marital satisfaction in mothers of primary school children. Journal of Life Science and Biomedicine. 2014; 4(2):119-24. http://jlsb.science-line.com/attachments/article/28/J.\%20Life\%20Sci.\%20Biomed.\%204(2)\%20 119-124,\%202014.pdf

[66] Falahatdoost M, Dolatshahi B, Mohammadkhani P, Nouri M. Identifying the role of early maladaptive schemas in variety of domestic violence against women with the experience of violence. Practice in Clinical Psychology. 2013; 1(4):219-25. http://jpcp. uswr.ac.ir/browse.php?a_id=127

[67] Hamamci Z. Dysfunctional relationship beliefs in marital conflict. Journal of Rational-Emotive and Cognitive-Behavior Therapy. 2005; 23(3):245-61. [DOI:10.1007/s10942-005-0013-y]

[68] Amani A, Eisanejad O, Azizi A. [Study of the structural relations of early maladaptive schemas, personality factors and marital adjustment (Persian)]. Journal of Modern Psychological Research (Tabriz University Psychology). 2015; 10(37):45-70. http:/ / ensani.ir/file/download/article/20160315121732-9957-80.pdf

[69] Zolfaghari M, Fatehi Zadeh M, Abedi M. [Determining relationships between early maladaptive schemas and marital intimacy among mobarakeh steel complex personnel (Persian)]. Journal of Family research. 2008; 4(3):247-61. http://ensani.ir/ file/download/article/20120329111524-2108-93.pdf

[70] Rafiee S, Hatami A, Foroughi A. [The relationship between early maladaptive schemas and attachment styles in women with infidelity (Persian)]. Journal: Sociology of women (Journal of Women and Society). 2011; 1(5):21-36. https://www.sid.ir/en/ journal/ViewPaper.aspx?ID=303216

[71] Yousefi R, Abedin Ar, Tirgari A, Fathabadi J. [The effectiveness of training intervention based on schema model on marital satisfaction enhancement (Persian)]. Journal of Clinical Psychology. 2010; 2(3):25-38. https://jcp.semnan.ac.ir/article_2027_7c4c71663 c3bb7e2fb136501db940139.pdf?lang=en

[72] Thimm JC. Mediation of early maladaptive schemas between perceptions of parental rearing style and personality disorder symptoms. Journal of Behavior Therapy and Experimental Psychiatry. 2010; 41(1):52-9. [DOI:10.1016/j.jbtep.2009.10.001] [PMID]
[73] Çalışkan B. Relationship between early maladaptive schemas, perceived maternal parenting style, emotion regulation difficulties and psyhological well-being [Unpublished MA. thesis]. İstanbul: Doğuş University Institute of Social Sciences; 2017. https://openaccess.dogus.edu.tr/xmlui/handle/11376/2975

[74] Bosmans G, Braet C, Van Vlierberghe L. Attachment and symptoms of psychopathology: Early maladaptive schemas as a cognitive link? Clinical Psychology \& Psychotherapy. 2010; 17(5):37485. [DOI:10.1002/cpp.667] [PMID]

[75] Roemmele M, Messman-Moore TL. Child abuse, early maladaptive schemas, and risky sexual behavior in college women. Journal of Child Sexual Abuse. 2011; 20(3):264-83. [DOI:10.1080/1 0538712.2011.575445] [PMID]

[76] Specht MW, Chapman A, Cellucci T. Schemas and borderline personality disorder symptoms in incarcerated women. Journal of Behavior Therapy and Experimental Psychiatry. 2009; 40(2):256-64. [DOI:10.1016/j.jbtep.2008.12.005] [PMID]

[77] Erfan A, Noorbala AA, Amel SK, Mohammadi A, Adibi P. The effectiveness of emotional schema therapy on the emotional schemas and emotional regulation in irritable bowel syndrome: Single subject design. Advanced Biomedical Research. 2018; 7:72. [DOI:10.4103/abr.abr_113_16] [PMID] [PMCID]

[78] Eldoğan D, Barışkın E. Erken dönem uyumsuz şema alanları ve sosyal fobi belirtileri: Duygu düzenleme güçlügünün arac1 rolü var m1. Türk Psikoloji Dergisi. 2014; 29(74):108-15. https:/ www.psikolog.org.tr/tr/yayinlar/dergiler/1031828/tpd1300443320140000m000051.pdf

[79] Di Pierro R, Benzi Ima, Madeddu F. Difficulties in emotion regulation among inpatients with substance use disorders: The mediating effect of mature defenses mechanisms. Clinical Neuropsychiatry. 2015; 12(4):83-9. https://www.researchgate.net/ profile/Ilaria-Benzi/publication/283872749_

[80] Manzaree Tavakoli F, Bagheri M. The mediating role of stressmanagement related to difficulties in emotion regulation and psychological welfare in resident female students of Isfahan University dormitory. Journal of Scientific Research and Development. 2015; 2(2):112-5.

[81] Dvir Y, Ford JD, Hill M, Frazier JA. Childhood maltreatment, emotional dysregulation, and psychiatric comorbidities. Harvard Review of Psychiatry. 2014; 22(3):149. [DOI:10.1097/ HRP.0000000000000014] [PMID] [PMCID]

[82] Rellini AH, Vujanovic AA, Gilbert M, Zvolensky MJ. Childhood maltreatment and difficulties in emotion regulation: Associations with sexual and relationship satisfaction among young adult women. Journal of Sex Research. 2012; 49(5):434-42. [DOI:10 .1080/00224499.2011.565430] [PMID]

[83] Young JE, Klosko JS, Weishaar ME. Schema therapy: A practitioner's guide. New York: Guilford Press; 2003.

[84] Masomi R, Hejazi M, Sobhi A. The relationship between depression and early maladaptive schemas, obsessive rumination and cognitive emotion regulation. Indian Journal of Fundamental and Applied Life Sciences. 2014; 4(3):1159-70. https://www. semanticscholar.org/paper/

[85] Yakın D, Gençöz T, Steenbergen L, Arntz A. An integrative perspective on the interplay between early maladaptive schemas and mental health: The role of self-compassion and emotion regulation. Journal of Clinical Psychology. 2019; 75(6):1098-113. [DOI:10.1002/jclp.22755] [PMID] [PMCID] 